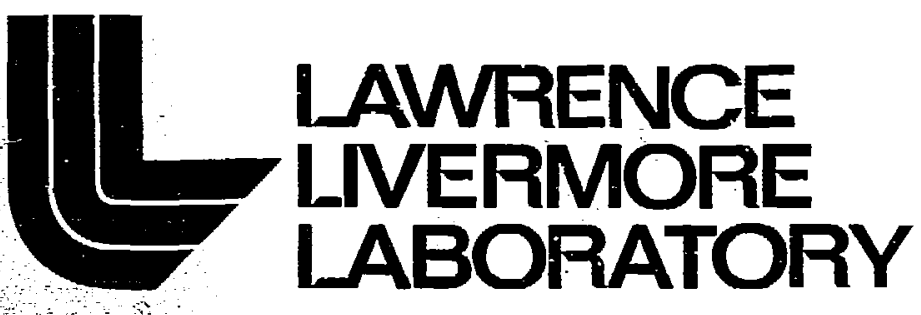

University of Califomia/Livermore 
TID-4500, UC-32

Mathematics and Computers

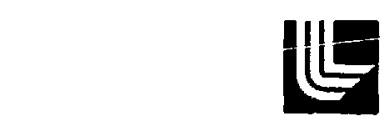

LAWRENCE LNERMORE LABORATOFY

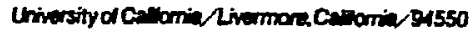

\section{UCRL-51462 \\ ADPIC \\ A THREE-DIMENSIONAL COMPUTER CODE \\ FOR THE STUDY OF POLLUTANT DISPERSAL AND DEPOSITION UNDER COMPLEX CONDITIONS}

Rolf Lange

MS. uste: October 18, 1973

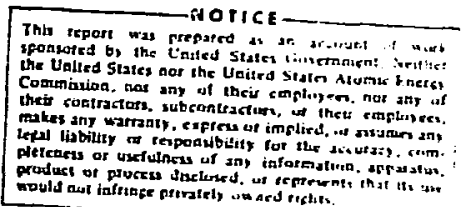

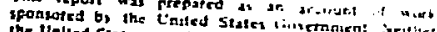

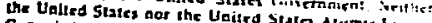

Complation, thas ant of their ength Afomis bners,

mates any ust

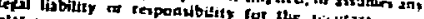

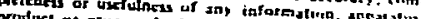

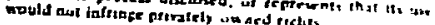




\section{Contents}

Abstract

Introduction

ADPIC Description

Pseudo-Velocity Nethod

Boundary Conditions

Topography

Flux boundary conditions

Options in ADPLC

Sources

Active pollutants

Deposition

Computer Cost

Scaling for ADPIC

Output

Washout versus Rainout

Diffusion Parameters

Horizontal Diffusivity Coefficients

Vertlcal Dlffusivity Coefficiont

Accuracy of ADPIC

Basic Finite Difference Algorithms • • . . . . • . . .

The Number of Eulerian Grid Cells Per Problem . . . . . 10

The Number of Particles Per Cell . . . . . . . . . 10

Particle Generation . . . . . . . . . . . . . 11

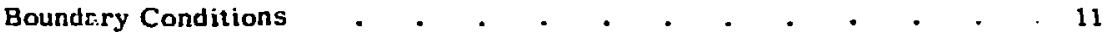

Time-Stc.- Calculation $\quad . \quad$.

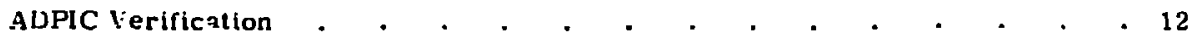

Instantaneous Sources (Puffs) • . . . . . . . . . . . 12

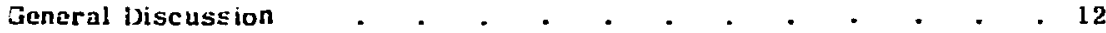

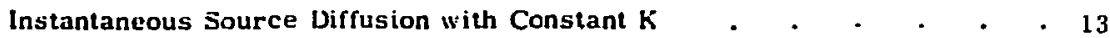

Instantaneous Source Diffusion with Scale Eependent $K(t) \quad$ - $\quad$ - . . 14

Instantaneous Source Diffusion in Simple Shear Flow - • . . . 16

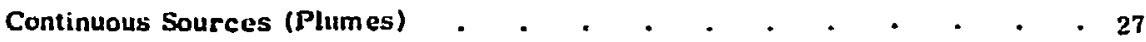

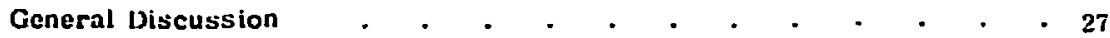

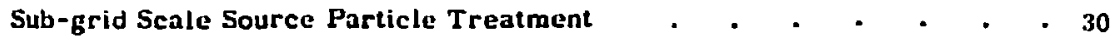

Continuous Source: Diffusion Only (Calm Conritiors) • • • • . 34

Continuous Sauree: Diffusion and Advection . . . . . . . . 39

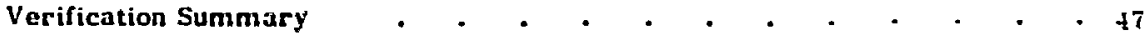

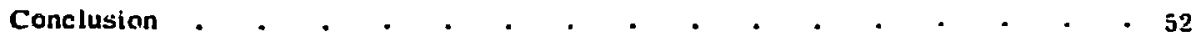

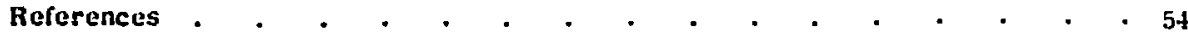




\title{
ADPIC \\ A THREE-DIMENSIONAL COMPUTER CODE FOR THE STUDY OF POLLUTANT DISPERSAL AND DEPOSITION UNDER COMPLEX CONDITIONS
}

\begin{abstract}
In line with the widening need and effort in the field of pollutant transport and diffusion studies from local to extended regional scales, it has become apparent that a fully three-dimensicral approach must be taken, and in order to do computer studies, three-dimensional computer codes must be developed. ADPIC is such a code. It is a threedimensional, Cartesian, particlediffusion code, capable of calculating the time-dependent dispersion of inert or radioartive air pollutants under many conditions, including stratified shear flow, calms, topography, and wet and dry deposition, for individual or multiple

instantaneous or continuous sources and space- and time-variable diffusion parameters.

The code solves the three-dimensional diffusion-advection equation by the pseudo-velocity technique for a given mass-consistent advection field. The method is based on the particle-in-cell technique with the pollutant concentration represented by Lagrangian particles in an Eulerian grid mesh. ADPIC has been verified for a number of selected advection-diffusion problems for which analytic solutions are available, and has been found to give results to within $\pm 5 \%$ of the analytic solutions.
\end{abstract}

\section{Introduction}

ADPLC (Atmospheric Diffusion Particle-in-Cell) is a numerical, threedimensional, Cartesian, particle-diffusion code capable of calculating the timedependent distribution of air pollutants under many conditions including strongly distorted advection wind fields, calm conditions, space variable surface roughness, wet and dry deposition, radioactive decay, and space- and lime-variable diffusion parameters.
Basically, the ccde solves the threedimensional advection-diffusion equation in its flux conservative form (pseudovelocity technique) for a given massconsistent advection field by finite difference approximations in $\mathrm{Car}^{\text {....... }}$ coordinates. The method is based on the particle-in-cell technique with the pollutant concentration represented statistically by imbedded Lagrangian marker particles in an Eulerian grid. ${ }^{1-3}$ 
The code has two versions: A movin expanding grid version and a fixed gric version. The moving, expanding grid version is primari'y designed to model single puff releases; the grid automatically expands and travels it itn the puff along its trajectory in the free atmosphere. This ver'sion is particularly suitable for the study of free-air bursts, or the long-range study of a surface release. The fixed grid version is suitable for the study of instantaneous or continuous releases near or on the surface over a range of scales, loosely defined from close-in ( 5 to $10 \mathrm{~km}$ ) to mid-range $(10$ to $200 \mathrm{~km}$ ).

\section{ADPIC Description}

\section{PSEUDO-VELOCITY METHOD}

The pseudo-velocity method consists of the following: Given the nonlinear transport-diffusion equation

$\frac{\partial x}{\partial t}+\bar{U}_{A} \cdot \bar{\nabla} x=\bar{\nabla} \cdot(K \bar{\nabla} x)$,

where $x$ is a scalar concentration, $K$ the diffusion coefficient and $\bar{U}_{A}$ the (given) mass-consistent wind advection field, under the assumption of incompressibility u. e san replace the $\overline{\mathrm{U}}_{\mathrm{A}} \cdot \bar{\nabla} \mathrm{X}$ term by $\bar{\nabla} \cdot(x U)$. Upon combining the two divergence terms, we can rewrite Eq. (1) in its flux conservative (pseudo velocity) form

$$
\begin{aligned}
\frac{\partial x}{\partial t}+\bar{\nabla} \cdot\left[x \left(U_{A}\right.\right. & \left.\left.-\frac{K}{x} \bar{\nabla} x\right)\right] \\
& =\frac{\partial x}{\partial t}+\bar{\nabla} \cdot\left(x \bar{U}_{P}\right)=0,
\end{aligned}
$$

where $\overline{\mathrm{U}}_{P}=\overline{\mathrm{U}}_{\mathrm{A}}-\frac{\mathrm{K}}{\bar{X}} \bar{\nabla} \mathrm{X}$ is the pseudo transport velocity.

The grid mesh of the code is represented by an Eulerian grid consisting of three-dimensional rectangular cells of uniform size. The concentrations $x$ are defined at the centers of the cells and the velocities $\overline{\mathrm{U}}_{\mathrm{A}}, \overline{\mathrm{U}}_{\mathrm{P}}$ and $-\frac{\mathrm{K}}{\mathrm{X}} \nabla \mathrm{x}$ are def:ned at the cell corners. The locations of the particles, which represent the pollutant clcid statistically, are defined by their individual Lagrangian coordinates within the Eulerian fixed grid.

A time cycle of the code is divided into an Eulerian step and a Lagrangian step and proceeds as follows:

- Eulerian Step: The concentrations $x$, giver for each celi at the beginning of the cycle, are used to calculate the difiusivity velocities $\mathrm{U}_{\mathrm{D}}=-\frac{\mathrm{K}}{\mathrm{\chi}} \bar{\nabla} \mathrm{x}$ which are then added to the given wind advection velocities $\bar{U}_{A}$ to yield a pseudo velocity $U_{P}$ for each cell corner.

- Lagrangian Step: Each marker particle contained in a given cell is transported for one time step $\Delta t$ with a velocity $\bar{U}_{P^{\prime}}$, which is computed from the pseudo-velocities $\overline{\mathrm{U}}_{\mathrm{P}}$ at the corners of the cell, and the particle coordinates $\bar{x}$ are determined by a volume weighting scheme

$\bar{x}($ new $)=\bar{x}($ old $)+\bar{U}_{P} \Delta t$. 
Finally, a new concentration

distribution $X$ is calculated from the new particle positions, thus ending the cycle.

The chief advantage of using such a hybrid Eulerian-Lagrangian scheme is that the fictitious diffusion inherent in a purely Eulerian scheme is eliminated. The truncation errors inherent in the finitie difference aigorithme remain, of course, and must be minimized by the choice of the time step.

\section{BOUNDARY CONDITIONS}

The boundary conditions are applied to a layer oi boundary cells that surround or protrude into the grid.

\section{Topegraphy}

Space-variable surface roughness in the form of topopraphy protrudes into the basic gril block of the code. The code recognizes individual flagged grid cells as topography and uses the applicable boundary conditions. The proper modeling of particle deposition on the ground is greatly dependent on the way topography is treated. Dry deposition and deposition by gravity is treated by specifying a deposition velecity at the topographic surface.

\section{Flux Boundary Conditions}

Flux boundary cozditions representing inflow or outflow of pollutant particles from the grid are cast in the form of conservation of total flux, $\left(\overline{\mathrm{U}}_{\mathrm{P}} \mathrm{X}\right)=$ constant [see Eq. (2)]. An inversion layer capping the region of interest can be specified by a -eflecting boundary cordition, whence the total flux $\left(\overline{\mathrm{U}}_{\mathrm{P}} \mathrm{X}\right)=0$ at the inversion layer. In the case of the moving, expand- ing grid version, the grid mesh will automatically expano when a pollutant particle from a growing puff enters a boundary cell.

\section{OFTIONS IN ADPIC}

\section{Sources}

Pollutani sources can be generated any where within the grid mesh or on an inflow boundary. When the pollutant distribution to be studied covers less than two grid cell lengths, the code diffuses the particles too slowly, ao that for the case of sub-grid scale sources a special sub-grid treatment of the special source particles is employed.

\section{Active Follutants}

The way in which ADPI I describes poliutants in terms of discrete mass (activity) particles makes the implementation of decay rate calculations very straightforward. Surh processes as radioactive decay or prompt $\gamma$-ray dose (cloudshine) of pollutants in conjunctic. with atmospheric dispersion under complex conditions can be modeled.

\section{Deposition}

Surface deposition from gravity or turbulent impaction and washout of pollutants from rain clouds and the ensuing ground surface concentrations are modeled by cumulatively storing those particles that have reached the ground in a special two-dimensional deposition array.

\section{COMPUTER COST}

ADPIC requires large amounts of core storage space. Four three-dimensional 
arrays arise from the Eulerian part of the time cycle: the concentration $\chi(I, J, K)$, and the three velocity components $\bar{U}(I, J, K), \bar{V}(I, J, K)$, and $\bar{W}(I, J, K)$. The total size of the arrays is the number of grid cells $(I \times J \times K)$. Four onedimensional arrays arise from the Lagrangian part of the time cycle: the particle coordinates $X(N), Y(N)$, and $Z(N)$ and the particle mass $M(N)$. Here $N$ is the total number of ADPIC particles. Ir. addition to these basic arrays, the boundary conditions and various options of the code require a good deal of computer memory storage. It is expected that most of the usable large core memory (about 340090 decimal worts) of a CDC 7600 computer will be needed to run AUPIC in its final form for a regional study. A rough upper limit size for such a problem would be 25000 cells $(50 \times 50$ in the horizontal $\times 10$ in the vertical) and 30000 particles.

The estimation of computer time for such a problem is presently speculative. Most of the verification studies were run for a 3375-cell grid $(15 \times 15 \times 15)$ with 4000 particles at roughly $0.01 \mathrm{~min} /$ cycle. The 25 000-cell, 30 000-particle regional grid is about seven times larger; hence, one might expect a computer time uí 0.07 min/cycle. This is a computational speed about 100 times Easter than the real-time value of $8 \mathrm{~min} / \mathrm{cycle}$ that one would fxpect for a $5-\mathrm{km}$ horizontal grid cell length and a $5-\mathrm{m} / \mathrm{sec}$ mean wind.

\section{Scaling for ADPIC}

Assuming that a $25000-c e l l, 30000-$ parîcle fixed grid size problem is a practical maximum size for ADPIC, based on the computer memory core limitations discussed above, the resolution provided by the grid cells of such a problem can be discussed with regard เ二 the distance scale of interest for a release study :

- Close-in (1 to $5 \mathrm{~km}$ ). Each grid cell would correspond to from 20 to $100 \mathrm{~m}$ in the horizontal, roughly equivalent to the source size. Building wake effects, în example, in ay be studied on that scale.

- Mid-range $(10$ to $200 \mathrm{~km})$. On this scale, the individual grid cell would correspond to from $200 \mathrm{~m}$ to $4 \mathrm{~km}$ in the horizontal. This would provide sufficient resolution to study the regional dispersion of pollutants away from the source. However, as has been pointed out, when the standard deviation of a pollutant distribution $\sigma_{x}$ is equal to or less than $\Delta X$, where $\Delta X$ is the grid cell length, ADPIC does not diffuse pollutants fast enough. Thus the lower bound on $\sigma_{x}$ for a valid ADPIC calculation in this mid-range case lies between $400 \mathrm{~m}$ and $8 \mathrm{~km}$.

If the close-in shape of the distribution from a continuous source is known as a function of time, e.g., if $\sigma_{x}(t)$ is known for a Gaussian distribution, then sub-grid scale point sources can be treated directly in the mid-range scale problem. This may be the case for some ideal circumstances, but most probably. to be able to initially resolve a pollutant distribution that originates from a continuous 20-m large source with a mid-range grid scale, one must use a special method for providing an extended source that 
is released into the mid-range problem. Similar scaling remarks hold, of course, in the vertical.

- Distant range (out to $1000 \mathrm{~km}$ ). For this range, to retain the necessary resolution of the debris cloud, ADPIC should most likely be used in its moving-expanding grid version in a single or sequential puff approach to the study of an established plume. In this case, the ADPIC grid follows mean advection trajectory of the debris cloud and expands as the cloud expands.

\section{OUTPUT}

ADPIC's main output is pollutant concentration per grid-cell volume in terms of number of particles per cell and mass per particle as functions of time and grid cell location, from which either the cloud center or surface air concentration can be obtained in $\mathrm{Ci} / \mathrm{m}^{3}$ or $\mathrm{g} / \mathrm{m}^{3}$.

Additionally, a special two-dimensional grid cell array keeps track of the cumulative deposition of pollutant on the surface in terms of pollutant radioactivity per grid cell area $\left(\mathrm{Ci} / \mathrm{m}^{2}\right.$ or $\left.\mathrm{g} / \mathrm{m}^{2}\right)$.

Because the coordinates of each ADPIC particle are stored, sampling volumes other than grid cells can be used to. obtain concentrations at the desired locations.

\section{WASHOUT VERSUS RAINOUT}

At present, the basic assumption for modeling removal of debris particles in ADPIC is that the base of the rain cloud is above the debris cloud and thus does not protrude into the ADPIC grid mesh from above. For surface or near-surface pollutant releases, this seems to be a reasonable assumption, certainly for the close-in range and probably for most of the mid-range to about $100 \mathrm{~km}$ downwind. Thus, ADPIC will not treat in-cloud rainout, but has provisions for belowcloud washout.

Washout is treated in the following way in ADPIC. For a speciried rain rate prevailing over a given surface area, a washout coefficient $\Lambda(r)$ is assumed as a function of debris particles of size $r$. Because of their limited number, each ADPIC particle is much larger than a debris particle. Therefore, an ADPIC inass particle is initially considered to represent an integrated debris particle size distribution over sizes such that

$$
M(0)=\int_{r=0}^{\infty} m(r, 0) d r,
$$

where $M(0)$ is the initial mass of an ADPIC particle and $m(r, 0)$ is the mass per unit radius of a debris particle of radius $r$ at time 0 . Constant density is assumed for the debris particles. $M(t)$, the mass of an ADPIC particle remaining after a time $t$ in the rain for a given constant rain rate and raindrop size distribution, can then be written as 4

$$
\begin{aligned}
M(t) & =\int_{r=0}^{\infty} m(r, t) d r \\
& =\int_{r=0}^{\infty} m(r, 0) e^{-\Lambda(r) t} d r
\end{aligned}
$$

To account for the diffusion and transport of pollutant as calculated by ADPIC, this 
function $M(t)$ is computed lor looked up from a table) at each ADPIC time step $\Delta t$. The fraction of mass $F(\Delta t)$ of an ADPIC particle washed out and deposited on the surface during one ADPC time cycle then becomes

$$
\begin{gathered}
F(\Delta t)=\frac{M(t)-M(t+\Delta t)}{M(t)}=1 \\
-\frac{\int_{r=0}^{\infty} m(r, 0) e^{-\Lambda(r)(t+\Delta t)} d r}{\int_{r=0}^{\infty} m(r, 0) e^{-\Lambda(r) t} d r} .
\end{gathered}
$$

This fraction of mass loss per cycle for each ADPIC particle is stored cumulatively each cycle in a two-dimensional, surface deposition array.

\section{DIFFUSION PARAMETERS}

Because ADPIC is a three-dimensional Cartesian code and uses the turbulent flux diffusivity pseudo-velocity

$$
\vec{U}_{D}=-\frac{\bar{K}}{x} \vec{\nabla} x,
$$

to model diffusion, it can in principle accommodate the full Cartesian eddy diffusivity tensor $\overline{\overline{\mathrm{K}}}=\mathrm{K}_{\mathrm{ij}}$. In practice, isotropy of turbulence in the atmosphere is assumed, and only the diagonal terms $\mathrm{K}_{\mathrm{xx}}, \mathrm{K}_{\mathrm{yy}}$, and $\mathrm{K}_{\mathrm{zz}}$ survive. In addition, it is generally assumed that the horizontal components of the diffusivity coefficients are the same, so that $\mathrm{K}_{\mathbf{x x}}=\mathrm{K}_{y \mathbf{y}}$. Even with these simplifications, the capability of ADPIC to model diffusion in threedimensions with topography and inversions, under conditions of wind shear and with space- and time-variable diffusivity coefficients, cannot presently be fully exploited largely because of the lack of a unified theory of diffusion in the atmosphere from which such diffusion coefficients can be obtained. Consequently, at least as a starting point, the various tested partial theories of diffusion in the atmosphere must be combined in a consistent way to provide diffusion coefficients for ADPIC.

For present purposes, diffusivity coefficients must be found that are valid for single puff or continuous plume releases which can grow from sources on the order of meters in size to debris clouds on the kilometer scale. When we consider time periods on the order of $12 \mathrm{~h}$ and geographical radii of interest on the order of $100 \mathrm{~km}$, we are in a range where turbulent diffusivities are scale-dependent, Additionally, since the debris cloud may extend vertically through the entire turbulent mixing layer, the state of the thermal stability of the atmosphere must be taken into account. Constant K-theory will not be adequate for such requirements, and similarity theories will be chosen as the primary available framework upon which to base horizontal and vertical diffusivity coefficients for ADPIC.

\section{Horizontal Diffusivity Coefficients}

A large number of experimental studies have been summarized ${ }^{5}$ to show the validity of similarity theury in the inertial subrange of the atmosphere, as originally proposed by Kolmogoroff and discusseci by Batchelor, ${ }^{6-8}$ for the horizontal spreading of clouds in the atmosphere from meter to kilometer sizes over times from minutes to several 
days. The conclusion drawn is that for such scales the horizontal diffusivity coefficients take the form

$$
K_{x x}=K_{y y} \propto \epsilon^{1 / 3}\left(\overline{\left.\sigma_{x}^{2}\right)^{2 / 3}},\right.
$$

whera $\epsilon$ is the rate of eddy-energy transfer in the inertial range and is a scaled function of height $\mathbf{Z}$ and average horizontal windspeed $\bar{U}(Z)$ above the surface,

$$
\epsilon \propto \frac{[\overline{\mathrm{U}}(\mathrm{Z})]^{3}}{\mathrm{Z}},
$$

and $\overline{\sigma_{x}^{2}}$ is the average horizontal dispersion of the cloud. For early times, when the initial cloud size in terms of its standard deviation $\sigma_{0}$ is important, the time rate of change of the dispersion is proportional to time $t$,

$$
\frac{\mathrm{d}\left(\overline{\sigma_{x}^{2}}\right)}{\mathrm{dt}} x\left(\epsilon \sigma_{0}\right)^{2 / 3} \mathrm{t}
$$

At late times, when $\sigma_{0}^{2}<<\overline{\sigma_{x^{\prime}}^{2}}$ the time rate of change of the dispersion becomes

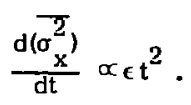

\section{Vertical Diffusivity Coefficient}

For the vertical diffusivity coefficient $\mathrm{K}_{\mathrm{zz}}$, the turbulent diffusion due to both the mechanical shear induced by the drag of the earth's surface on the atmosphere and the vertical thermal convection within the atmosphere must be taken into account. Within the first 50 to $100 \mathrm{~m}$, the so-called surface laycr of the atmosphere, the original similarity concepts of Obukhov, ${ }^{9}$ based on constant momentum and heat flux, have been thoroughly analyzed and tested experimentally. ${ }^{10-19}$ The results can be considered as ample verification for choosing the Monin-Obukhov similarity parameter $\xi=Z / L$, where $L$ is the Monin-Obukhov length and $\mathrm{Z}$ is the vertical height, as the primary independent variable representing the state of stability of the atmosphere in the surface layer to obtain the vertical diffusivity coefficient $\mathrm{K}_{\mathrm{zz}}$ ( $\boldsymbol{\xi} ;$. The functional relationship under this approach for $\mathrm{K}_{\mathrm{zz}}$ is

$$
\mathrm{K}_{\mathrm{zZ}}=\mathrm{i}, \mathrm{kZ} \frac{1}{\Phi_{\mathrm{m}}}=\left(\frac{\mathrm{kZ}}{\Phi_{\mathrm{m}}}\right)^{2} \frac{\partial \mathrm{U}}{\partial \mathrm{Z}}
$$

where $U_{\%}$ is the friction velocity, $k$ is the von Karman constant, $\Phi_{m}=\frac{k Z}{\bar{U}_{*}} \frac{\partial \bar{U}}{\partial Z}$ is a dimensionless wind shear, and $\bar{U}$ is the average horizontal windspeed. The function $\phi_{\mathrm{m}}$ depends in the following way on the stability of the atmosphere:

Stable: $\phi_{\mathrm{m}}=1+\gamma_{1} \xi$,

$$
\xi>0, L>0
$$

Neutral: $\Phi_{\mathrm{m}}=1$,

$$
\xi=0, L \rightarrow \infty
$$

Unstable: $\star_{m}=\left(1-\gamma_{2} \xi\right)^{-1 / 4}$.

$$
\xi<0, \mathrm{~L}<0 \text {. }
$$

Here $\gamma_{1}$ and $\gamma_{2}$ are empirical constants on the order of 4 to 5 and 14 to 16 , respectively. For neutral conditions, $\phi_{\mathrm{m}}=1, \xi=0$, and $L \rightarrow_{\infty}$ The Obukhov length $L$ has the form

$$
L=-\frac{\mathrm{U}_{*}^{3} \mathrm{C}_{\mathrm{p}} \rho \mathrm{T}}{\mathrm{kg} \mathrm{H}},
$$


where $C_{p}$ is the specific heat of air at constant pressure, $\rho$ the density of air, $T$ the temperature, $H$ the heat flux, and g the gravitational acceleration. Where $L$ is not known, it can be found from its functional reletionship to the Richardson number, $R_{i}$, for example. 19

Above the surface layer and up to the turb:llent mixing height, turbulence due to the surface stress eddies, thermal convection and $w$ ind shear decreases with height until it essentially disappears at the top of the mixing layer. ${ }^{20}$ The similarity assumptions of constant momentum and heat flux are no longer valid in this region, and very little consensus exists among investigators at the present time as to the values of vertical diffusion parameters. ${ }^{21}$ This is largely due to the complex interactions of wind shear, lapse rate, Coriolis force, pressure gradients, eddy diffusivity, buoyant plumes, and topography in this region. It is generally assumed that the vertical diffusivity coefficient $\mathrm{K}_{2 \mathrm{z}}$ either remains constant up to the mixing or inversion height, where it sharply drops to a minimum value, or goes to a minimum there with some smooth functional dependence on height above the surface layer. In general, $K_{z z}$ appears to be a strong function of the lapse rate. 22

Another reasonable starting point for obtaining a value for $\mathrm{K}_{\mathbf{z z}}$ for ADPIC above the surface layer will be to rely on a statistically obtained power law profile for the vertical standard deviation $\sigma_{z}$ of the form

$$
\sigma_{z}=a \sigma_{3} x^{b}
$$

where $a$ and $b$ are observationally obtained stability category constants, $\sigma_{\theta}$ is the horizontal wind nuctuation respectively, and $x$ is the downwind distance from the source. From the relation between $K$-theory and statistical diffusion theory, the vertica! diffusivity coefficient $\mathrm{K}_{22}$ then becomes

$$
\frac{d[\sigma(t)]^{2}}{d t}=2 K_{22}
$$

where $t$ is the time of travel from the release point. $23-25$

In conclusion, with the fiexibility available in ADPIC for assigning diffusion parameters, the basically accepted methods for their description, by empirical power law profiles coupled with stability categories and by Kolmogoroff's and Monin-Obukhov's L similarity theories, can be combined to give a starting point for a widened capability to model diffusion and transport of pollutants in the atmospheric toundary layer. Currently, a great deal of research effort is being expended on turbulent diffusion in the atmosphere, including the study of vertical gradients of wind and temperature profiles. Resulting descriptions of diffusion parameters can be quickly incorporated into ADPIC once they are consolidated and verified sufficiently to be considered operational.

\section{ACCURACY OF ADPLC}

Because the ADPIC time cycle is half Eulerian and half Lagrangian and because the original particle placement is determined by a random number generator, the discussion of the accuracy of ADPC must remain largely empirical. 
Five major factors contribute to the accuracy of the ADPIC method, and they will nov: be discussed in turn.

\section{Basic Finite Difference Algorithms}

As mentioned before, the cell concentrations are defined at the cell centers and the pseudo velocities $\bar{U}_{p}$ are defined at cell corners. The pseudo velocities contain both the advection velocities $\vec{U}_{A}$ and the diffusion velocities $\overrightarrow{\mathrm{U}}_{\mathrm{D}^{*}}$ Figure I shows this and the diffusion velocity algorithm resulting from this arrangement, displayed in a reduction to two dimensions for simplicity. The algorithm for the diffusivity velocity $U_{D}$ has an upper limit $\left|U_{D}\right|=2 \frac{K}{\Delta X}$ where $K$ is the diffusion parameter and $\Delta \mathrm{X}$ is the length of the cell. This feature prevents particles that are near the edge of a distribution, where there may be cells with just one particle interspersed with empty cells, from being moved too fast because of excessive diffusıon velocities that occur under such conditions when the velocity and concentration grid is not staggered. For example, the algorithm for the diffusion velocity in a nonstaggered grid requires three cells,

$$
\begin{aligned}
& \frac{|x . U| x . U|x, U|}{i-1 \quad i+1} \\
& u_{i}=-\frac{K}{2 \Delta X} \frac{\left(x_{i+1}-x_{i-1}\right)}{x_{i}} \text {. }
\end{aligned}
$$

It can easily be seen that if $x_{i}=0, u_{i} \rightarrow \infty$ The truncation errors contained in the ADPIC diffusion velocity algorithm can be investigated by expanding it in a Taylor series. Consider the one-dimensional case,

$u_{i+1 / 2}=-\frac{k_{i+1 / 2}}{\Delta X} \frac{\left(x_{i+1}-x_{i}\right)}{x_{i+1 / 2}}$.
Let the subscript be dropped for $i+1 / 2$ and expand $x_{i+1}$ and $x_{i}$ in Taylor series about $i+1 / 2$ to the first contributing error term:

$$
\begin{aligned}
U & =-\frac{K}{\Delta x \cdot x}\left[x+x^{\prime} \frac{\Delta x}{2}+\frac{1}{2} x^{\prime \prime}\left(\frac{\Delta x}{2}\right)^{2}\right. \\
& +\frac{1}{6} x^{\prime \prime \prime}\left(\frac{\Delta x^{2}}{2},-\left\{x-x^{\prime} \frac{\Delta x}{2}\right.\right. \\
& \left.\left.+\frac{1}{2} x^{\prime}\left(\frac{\Delta x}{2}\right)^{2}-\frac{1}{6} x^{\prime \prime}\left(\frac{\Delta x}{2}\right)^{2}\right\}\right] ; \\
U & =-\frac{K}{\Delta x \cdot x}\left[x^{\prime} \Delta x+\frac{1}{24} x^{\prime \prime}+\Delta x^{3}\right] \\
& =-\frac{K x^{\prime}}{x}-\frac{k}{24} \frac{x^{\prime}+1}{x} \Delta x^{2} .
\end{aligned}
$$

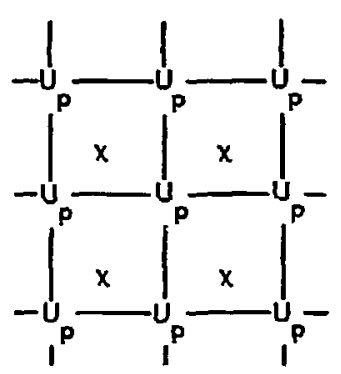

2-dimensional view

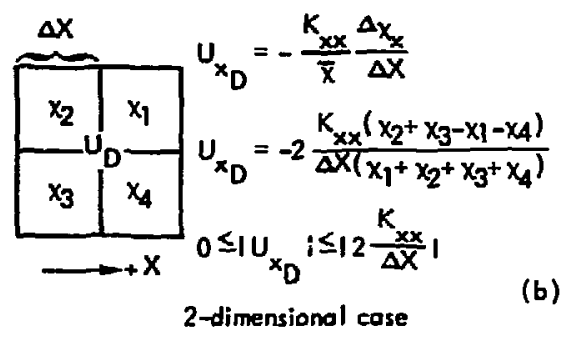

Fig. 1, Velocity algorithm. (a) grid mesh; (b) diffusivity. 
The first term on the righthand side is the exact differential expression for the diffusivity velocity; the second term is the first contributing error term. Forming the ratio of the ADPIC diffusion velocity, Eq. (20), to the exact differential diffusion velocity, we obtain a measure of the importance of the error term

$$
\frac{v_{A D P I C}}{U_{E X A C T}}=1-\frac{x^{1}+2}{x^{1}} \frac{(\Delta X)^{2}}{24} .
$$

For most problems, the third derivative $x^{\prime \prime \prime}$ is sufficiently smaller than the first derivative $X^{\prime}$ so as to make the error term small.

The Number of Eulerian Cells per Problem

It is important to have enough grid cells to resolve a given particle distribution well enough to make the concentration gradients calculated from the cell concentrations representative of the actual gradients. While the particle positions per cell may indicate some sub-grid resolution, it is important to point out that the numerical solutions of the diffusion equation are defined on the Eulerian grid. To get a feeling for how well a distribution must be resolved to give reasonable answers, consider Eq. (23) above for the case of a one-dimensional Gaussian distribution:

$$
x=\frac{Q}{\sigma} e^{-x^{2} / 2 \sigma^{2}}
$$

Let us find the derivatives $x^{\prime}$ and $x^{\prime \prime}$ '

$$
x^{\prime}=-\frac{Q X}{\sigma^{3}} e^{-x^{2} / 2 \sigma^{2}}
$$

$x^{\prime}+1=\frac{Q X}{\sigma^{5}}\left[3-\frac{X^{2}}{\sigma^{2}}\right] e^{-x^{2} / 2 \sigma^{2}}$.

Substituting Eqs. (25) and (26) into (23), we obtain

$\frac{U_{A D P I C}}{U_{\text {EXACT }}}=1-\frac{1}{2 q}\left(\frac{x^{2}}{\sigma^{2}}-3\right) \frac{\Delta X^{2}}{\sigma^{2}}$.

Using the fact that $99 \%$ of all particles in a one-dimensional Gaussian distribution lie within $x=3 \sigma$, we can substitute $x=3 \sigma$ in Eq. (27) and obtain

$\frac{U_{\text {ADPIC }}}{U_{\text {EXACT }}}=1-\frac{\Delta X^{2}}{4 \sigma^{2}}$.

This indicates that when the cell size $\Delta \mathrm{X}$ is large compared to the standard deviation of a particle distribution, ADPIC diffuses too slowly.

It appears that Eq. (27) indicates that for $\mathrm{X}^{2}=3 \sigma^{2}$ the crror term vanishes regardless of the grid spacing. In this case, $x^{\prime \prime}=0$ and higher-order derivatives in the Taylor expansion of $x$ must be retained to get a meaningful expression.

\section{The Number of Particles per Coll}

Inasmuch as the ADPIC particles represent a quantized density, it is desirable to have as many particles per cell as possible. The upper limit of this number is obviously dictated by computer storage. ADPIC assigns a fictitious cell volume to each particle of the same size and shape as the basic grid cell. Thereby, in calculating the concentration field from the particles, each particle will contribute some fractional part of its mass to eight nearest-neighbor cells in 
proportion to the overlap of its "volume" with the cell volumes of the neighbor cells. This procedure smoothes out the concentration field and in return the diffusion velocity field which is computed from it, and is consistent with the fact that the Eulerian part of the cycle cannot resolve sub-grid-scale phenomena. As the result of many problems run it can be said that, empirically, due to this smoothing technique as few as one particle per cell on the average will yield meaningful results. With fewer particles per cell tian that, i.e., when particles have no neighbors with in one cell length around them, the ADPIC diffusivity velocity algorithm (see Fig. 1) moves the particle to a grid point and "freezes" it there.

\section{Particle Generation}

ADPIC uses a random number generator to generate input particle distributions, either of constant density or Gaussian. It has been found that generating a with Gaussian puff of standard deviation $\sigma$ with several thousand particles represents a fairly good sample population, and the generated particle distribution is close to Gaussian. However, in the case of continuous sources where particle economy dictates that no more than a few hundred particles can be generated per cycle, each batch appears somewhat "lumpy." The some extent, because of many such batches these lumps average out when the batches start overlapping and diffusing. But since a particle is moved with a weighted average velocity of the velocities at the eight corners of the cell it is in, lumps of particles that were generated very close together in space tend to hold together. As the most extreme example, two particles generated with exactly the same coordinates will never move apart. Individual flacement of thousands of source particles is extremely impractical even it a good way could be found to do it in the case of a Gaussian distribution. For the case of a particle distribution that is well resolved by ADPIC grid cells, a method has been found to "smooth" the random number generator distribution without disturoing the shape of the Gaussian distribution. This method will be discussed later under ADPIC Verification.

\section{Boundary Conditions}

Due to the part-Eulerian, partLagrangian makeup of ADPIC, the boundary conditions break up into one set of conditiuss imposed on the Eulerian velocity field and one set imposed on the Lagrangian particles. Both sets must be consistent with each other.

The advection velocity field is adopted entirely by ADPIC from MACAW, a computer code that calculates a MAss Consistent Advection Wind field similar to the method used by Dickerson, ${ }^{26}$ and will not be discussed further here other than to point out that it is compatible with the assumption in ADPIC of incompressibility and conservation of mass.

The two basic boundary conditions imposed on the pseudo-velocity field in ADPLC $\vec{U}_{P}=\vec{U}_{A}+\vec{U}_{D}$ are constant mass flux, $(X \bar{U})=$ constant, corresponding to inflow and outflow of particles, and zero mass flux $(X \bar{U})=0$, corresponding to reflection of particles from the boundary. There are intermediate cases as, for example, depesition of particles at the 
topography, in which case a deposition velocity is specified. The chief cause of error incurred by velocity boundary conditions that has stubbornly plagued numerical simulations of all kinds is the lack of ability to specify the outflow boundary conditions. In the kind of studies that ADPIC has so far been used for, the concentration field is smooth enough by the time it reaches the outflow boundary that the boundary velocities can be specified by postulating a constant flux of particles through the boundary grid cell layer.

The particle boundary conditions are very simple. If a particle has been found to have left the grid during a cycle, it is either annihilated or counted as deposited or is reflected, according to the type of boundary specified.

\section{TIME-STEP CALCULATION}

ADPIC stability is rather insensitive to the length of the time step per cycle; however, since the ith particle transport is done by a forward differencing scheme

$$
\bar{x}_{i}^{n+1}=\bar{x}_{i}^{n}+U_{p}^{n} \cdot \Delta T,
$$

diffusion accurs too fast when $\Delta I$ becomes too large. It has been found satisfactory to limit the transport of the fastest particle in the problem to not allow it to move further than one cell octant per time step. (In one dimension this is equivalent to half a cell length.) ADPIC finds the largest total velocity $U_{p}=U_{A}+U_{D}$ that any particle sees and computes the time step according to the following equation:

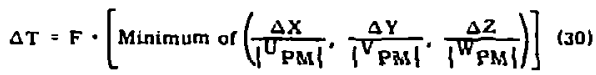

where $F$ is an input number between 0 and $1 / 2$ and $\Delta X, \Delta Y, \Delta Z$ are the cell lengths and $\left|U_{P M}\right|,\left|v_{P_{M}}\right|,\left|w_{P M}\right|$ are the absolute values of the maximum pseudo velocities at any cycle.

Finally, the time step $\Delta T$ is allowed to drop rapidly if required, but is limited to an increase of only a factor 1.3 from cycle to cycle to avoid instabilities.

\section{ADPIC Verification}

\section{INSTANTANEOUS SOURCES (PUFFS)}

\section{General Discussion}

All instantaneous source verification problems were run on the expanding grid version of ADPIC. In this version the Erio automatically expands by a given ratio independently in any of the three coordinate directions as soon as a particle is entering a boundary cell. In this manner boundary velocities need not be known and are set equal to zero, and no particles ever leave the grid. No matter how small the source, it can be resolved by the ADPIC grid from the beginning, and remains well resolved provided the puff does not get too distorted.

The initial Gaussian distribution of the particles is generated by calling a random-number generator. To generate a particle, the particle generator picks a random coordinate $X$ and then computes the Gaussian probability $P_{X}=\exp \left(-X^{2}\right)$ 
$2 \sigma_{0}^{2}$ ) that the particle would be found at that coordinate. It then picks another random number between zero and one. If this number is less than the probability $P_{X}$, the particle is "allowed." lif the number is greater than $P_{X}$, the particle is "disallowed" and a new $r$ andom coordinate $\mathrm{X}$ is picked and so on, until all particles are generated. To guard against too many disallowed particles at the edge of the distribution where $P_{X} \rightarrow 0$, there is a cutoff on the coordinate $X$ which is input into the code.

It was found that even for large samples of several thousand particles thus generated from the random generator, there were gaps and lumps of particles in the coordinate distribution. Further smoothing of the initial distribution was obtained in the following way: Since the total number of particles, the cell size of ADPJC, and the standard deviation of the Gaussian distribution to be generated are known, one can first compute the number of particles that should be contained in a given cell. After that, the random particle placement routine described above is employed for that cell by picking random coordinates within the cell until all particles for that cell are generated subject to the constraint of the Gaussian distribution. This method results in a considerably less lumpy distribution.

The following verification prolslems for puff diffusion were all compared against the analytic Gaussian solutions to the diffusion-advection equation as described for each problem. These are the solid lines in the following plots. The error bars shown for the ADPIC solutions were obtained by plotting the highest and the lowest particle concentration per cell as obtained by scanning four planes of symmetry for each problem in which the concentrations of corresponding cells should be the same. Because of the random nature in which the particles are generated, this corresponds essentially to running the same problem four times and sampling the same cell each time. The error bars thus are a good indication of the errors introduced by the quantization of density into particles and the above mentioned lumpiness of the random number generator. When the generator smoothing technique is not used, the error bars become roughly twice as large as the ones shown in the accompanying verification plots.

The following verification problems were run on ADPIC to study instantaneous sources: Number 3-2-15, puff diffusion with constant diffusion parameter $K$, $K_{\mathrm{xx}}=\mathrm{K}_{\mathrm{yy}} ; \mathrm{K}_{\mathrm{zz}}$; Number 3-3-24B, puff diffusion with scale-dependent $K$; Number 3-3-26, puff diffusion with constant $K$ in simple shear flow. These problems will now be discussed in turn.

Instantaneous Source Diffusion with Constant $K$

Problem 3-2-15 was run to compare ADPIC for the case of puff diffusion in three dimensions with constant $K$ with the Gaussian solution to the diffusion advection equation of the form 


$$
\begin{aligned}
x(x, y, z, t)=\frac{Q}{(2 \pi)^{3 / 2}\left(\sigma_{x 0}^{2}+2 K_{x x}\right)^{1 / 2}\left(\sigma_{y 0}^{2}+2 K_{y y}^{t}\right)^{1 / 2}\left(\sigma_{z 0}^{2}+2 K_{z z^{t}}{ }^{1 / 2}\right.} \\
\times \exp \left[-\frac{1}{2}\left(\frac{x^{2}}{\sigma_{x 0}^{2}+2 K_{x x}^{t}}+\frac{y^{2}}{\sigma_{y 0}^{2}+2 K_{y y}^{t}}+\frac{z^{2}}{\sigma_{z 0}^{2}+2 K_{z z} t}\right)\right] .
\end{aligned}
$$

A spherically symmetric Gausizian puff distribution of 3896 particles with a standard deviation of $\sigma_{0 x}=\sigma_{\text {vy }}=\sigma_{q \bar{z}}$ $=2 \Delta X$ was generated at the center of a $14 \times 14 \times 14$ originally cubical ADPIC grid of cell size $\Delta X=\Delta Y=\Delta Z=10 \mathrm{~m}$, and was allowed to diffuse. The diffusion parameters were $\mathrm{K}_{\mathrm{xx}}=\mathrm{K}_{\mathrm{yy}}=1 \times 10^{4}$ $\mathrm{cm}^{2} / \mathrm{sec}, \mathrm{K}_{\mathrm{zz}}=10 \mathrm{~cm}^{2} / \mathrm{sec}$. The problem ran 60 cycles and $286300 \mathrm{sec}$ during which time the grid expanded automatically many times, with the final cell size being $\Delta X=\Delta Y=394 \mathrm{~m}, \Delta \mathrm{Z}$ $=16.9 \mathrm{~m}$.

Figures 2 and 3 show the initial particle distribution at $\mathbf{T}=0, \quad$ Figure 4 shows the particle distribution at Cycle 60, $T=286300 \mathrm{sec}$ in the $X-Z$ plane. Figure 5 shows the same in the $X-Y$ plane. Figures 6 and 7 show the particle concentrations per original cell volume at Cycle 60 in the $X-Z$ plane along the $X$-axis and $Z$-axis respectively.

\section{Instantaneous Source with Scale-} Dependent $K(t)$

Problem 3-3-24B was run to compare ADPIC against an analytic solution for the case of scale-dependent diffusion.

It is shown in reference ${ }^{27}$ that the variance $\sigma^{2}$ of a Gaussian distribution crn be expressed in the following closed form for scale-dependent diffusion in the atmosphere:

$$
\sigma^{2}(t)=\left(\sigma_{0}^{2 / 3}+\frac{2}{3} C \epsilon^{1 / 3} t\right)^{3}
$$

where $\sigma_{0}$ is the original standard deviation of the distribution, $C$ a constant of order unity, $E$ is the enerEy dissipation rate in the atmosphere, and $t$ is time. When this expression is substituted into the expression for the similarity theory diffusivity parameter

$$
K(t)=C \epsilon^{1 / 3} \sigma^{4 / 3}(t)
$$

we obtain $K$ as a function of $\epsilon$ : time:

$$
K(t)=C \epsilon^{1 / 3}\left(\sigma_{\eta}^{2 / 3}+\frac{2}{3} C \epsilon^{1 / 3} t\right)^{2} .
$$

To match the observation that at very late times at the upper end of the turbulence scale $\mathrm{K}$ becomes a maximum constant $K_{\text {MAX }}$, Walton ${ }^{27}$ uses as a form for $K(t)$

$$
K(t)=\left[\frac{1}{K_{\text {MAX }}}+\frac{1}{K(t) \text { Eq. (34) }}\right]^{-1} \text {. }
$$

This $K(t)$ was put into ADPIC in the same form for $K_{y y}(t)$ and $K_{z z}(t)$, but with different constants. For $\mathrm{K}_{\mathrm{yy}}(\mathrm{t})$ : $\mathrm{K}_{\mathrm{yy}}{ }_{\operatorname{MAX}}=5 \cdot 10^{9} \mathrm{~cm}^{2} / \mathrm{sec}, \sigma_{\mathrm{yO}}=2^{n} 4 \mathrm{~m}$; and for $K_{z z}(t)$ : $\mathrm{K}_{\mathrm{zz}} \mathrm{MAX}=1 \cdot 10^{4} \mathrm{~cm}^{2} / \mathrm{sec}, \sigma_{\mathrm{z} 0}=33.4 \mathrm{~m}$. For both the $\mathrm{y}$ and $\mathrm{z}$ directions, $E=2.0$ and $C=1$. The results of ADPIC were 


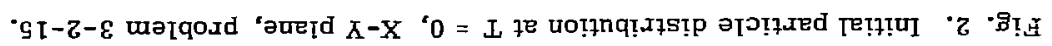

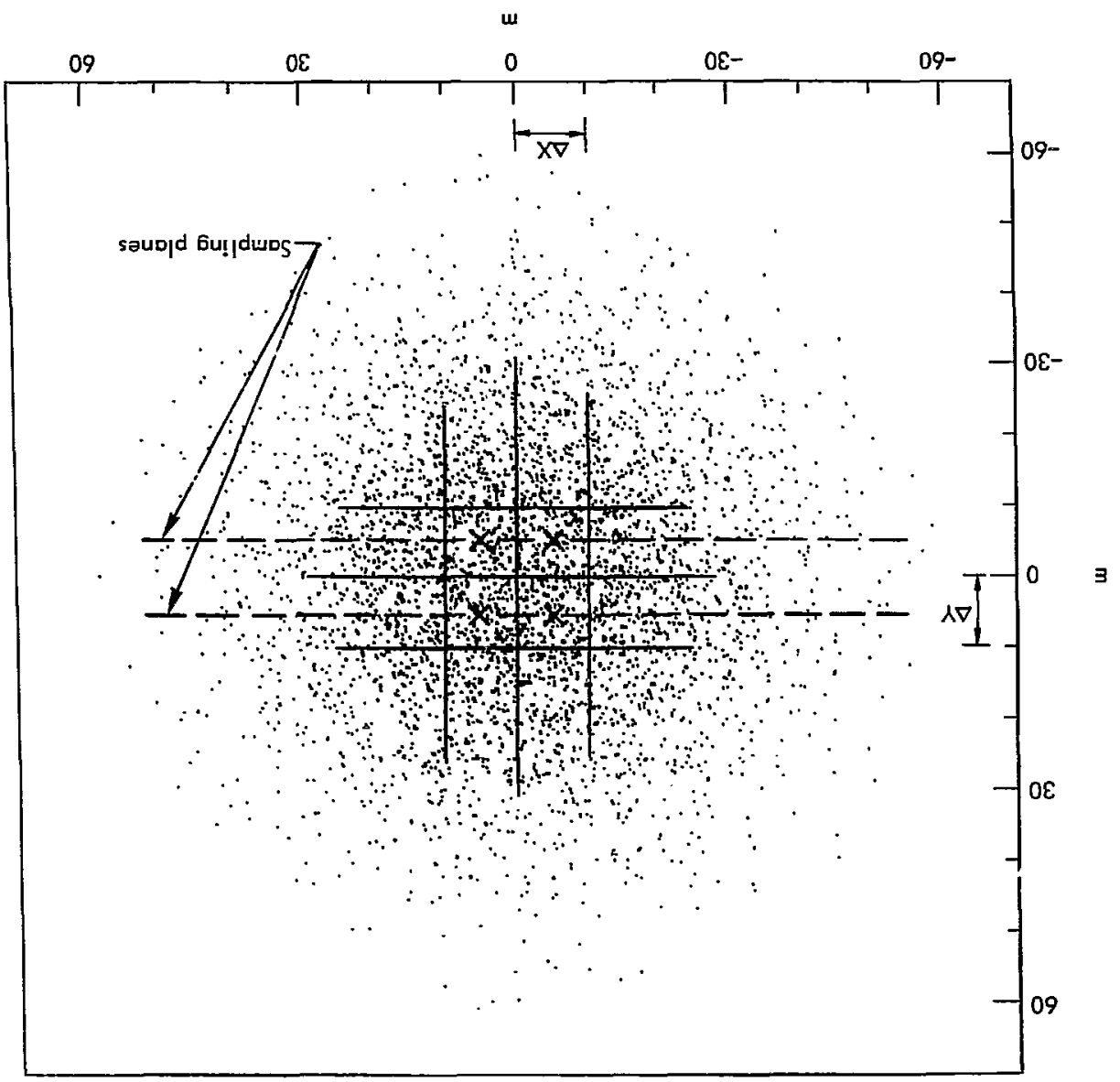




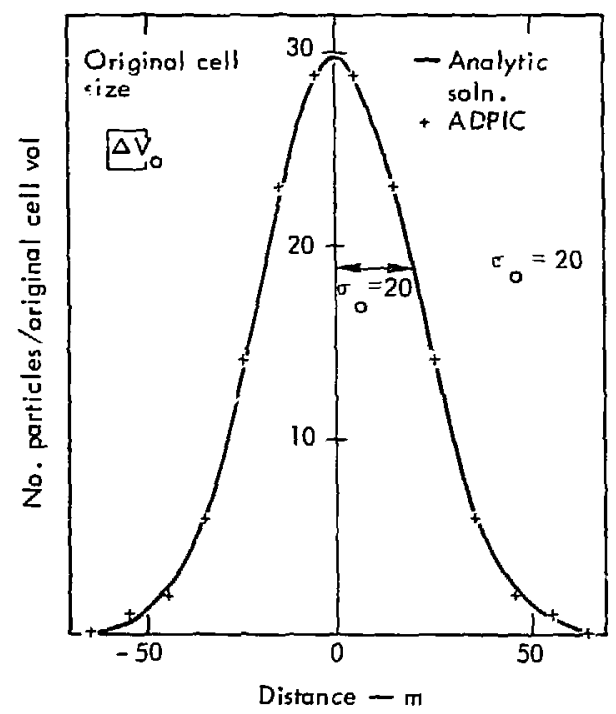

Fig. 3. Plot of initial particle distribution at $\mathrm{T}=0$. Problem 3-2-15.

compared with the analytic Gaussian solution to the diffusion-advection equation

$$
\begin{gathered}
x(y, x, t)=\frac{Q}{2 z\left(\sigma_{y 0}^{2}+2 k_{y y} \tau\right)^{l / 2}\left(a_{z 0}^{2}+2 K_{z z} T\right)^{1 / 2}} \\
x \cdot \exp \left[-\frac{1}{2}\left(\frac{y^{2}}{\left(a_{y 0}^{2}+2 K_{y y} T\right)}+\frac{z^{2}}{\left(a_{z 0}^{2}+2 K_{z z} \tau\right)}\right)\right] \quad(36)
\end{gathered}
$$

in which $\mathrm{K}_{\mathrm{yy}}$ and $\mathrm{K}_{\mathrm{zz}}$ are of the timedependent form of $\mathrm{Eq}$. (35).

ADPIC was run in a twro-dimensional mode in the $y-z$ plane for this problem with the $X$ dimension degenerate. This was achieved by allowing only four cells in the $X$ direction and setting $\sigma_{\mathrm{x} 0}$ in the particle generator equal to a very large number so that the probability that a particle can be found along the $x$-axis $\mathrm{P}_{\mathrm{x}}=\exp \left(-\mathrm{X}^{2} / 2 \sigma_{0 \mathrm{x}}^{2}\right)$ goes to one every where. As a result, the particle density in the $x$-direction is constant. In addition, $K_{x x}$ was set equal to zero everywhere and the particle flux set equal to zero at the $x_{\text {max }}$ and $x_{\text {min }}$ boundaries.

The number of particles initially generated in a two-dimensional Gaussian distribution was $3168 / \Delta X$ where $\Delta X$ is the cell width in the degenerate $\mathrm{X}$ direction. $\sigma_{0 \mathrm{y}}$ was $204 \mathrm{~m}$ and $\sigma_{\mathrm{z} 0}$ was $33.4 \mathrm{~m}$. The number of cells was $4 \times 14$ $x 14$ in the $x, y, z$ direction respectively. The problem was run to 100 cycles, $T=37720$ sec. Figures 8 and 9 show the particle distribution at cycle 0 in the $y$ and $z$ dimensions. Figures 10 and 11 show the same at cycle 100, $T=88720$. Figure 12 is a plot of relative particle concentration per cell at cloud center versus time.

Instantaneous Source Diffusion in Simple Shear Flow

Problem 3-3-26 was run to compare ADPIC with the analytic solution of Quesada $^{28}$ for puff diffusion in shear flow. The analytic solution advanced by Quesada 28 is of the form

$$
\begin{aligned}
& \frac{x(x, y, z, t)}{x_{0}} \\
& \quad=\frac{\exp \left[-y^{2} /(1+4 \tau)\right] \exp (-F / G)}{[(1+4 \tau) G]}[/ 2
\end{aligned}
$$

where

$$
\begin{aligned}
& F=\left(x^{\prime}-\mu z^{\prime} \tau\right)^{2}(1+4 \tau) \\
& +4 \mu z^{\prime} \tau^{2}\left(x-\mu z^{t} \tau\right)+z^{t^{2}} \\
& X\left(1+4 \tau+\frac{4}{3} \mu^{2} \tau^{3}\right) \\
& G=(1+4 \tau)^{2}+\frac{4}{3} \mu^{2} \tau^{3}(1+\tau),
\end{aligned}
$$

all expressed in the dimensionless quantities 


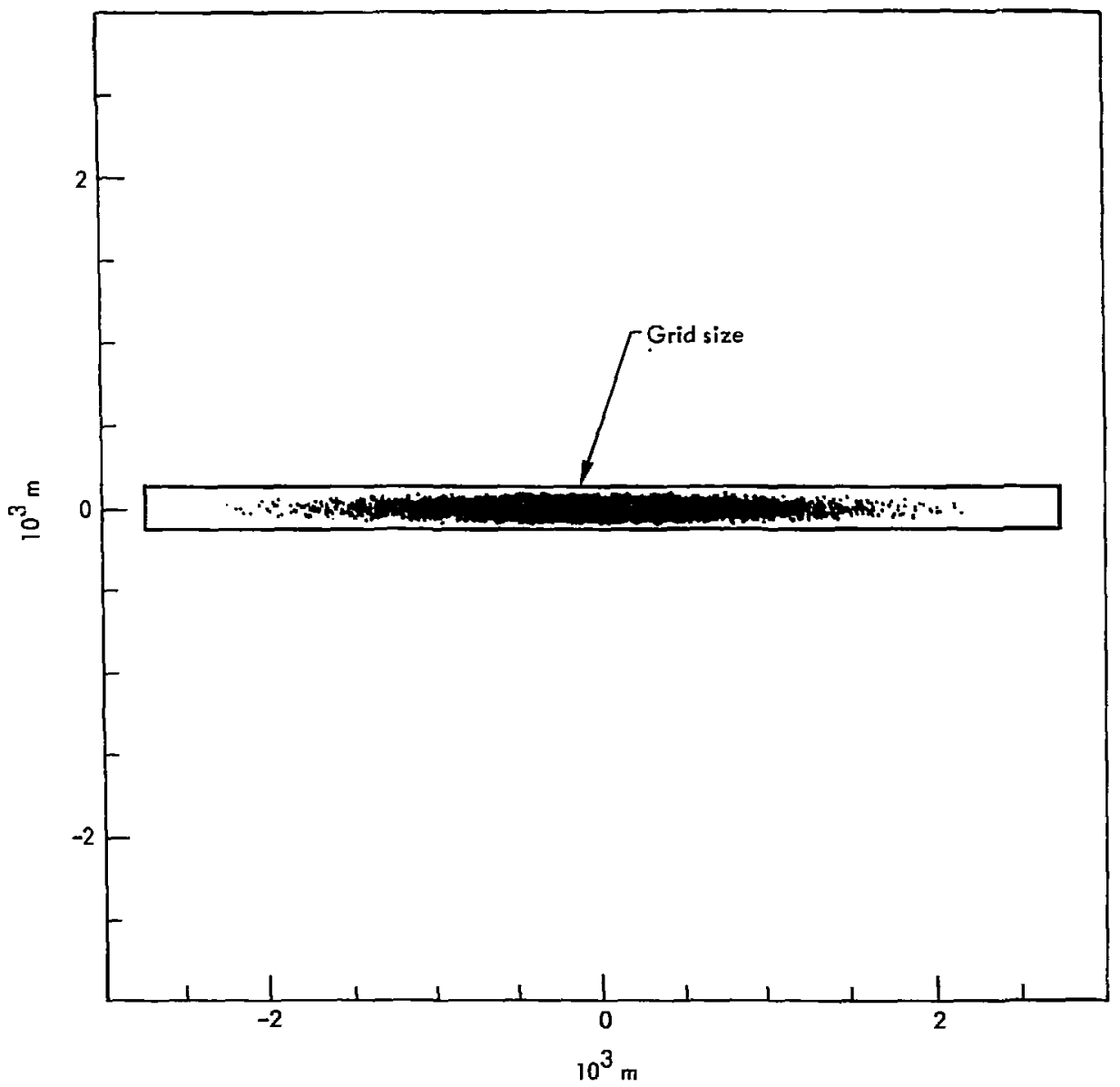

Fig. 4. Particle distribution at Cycle 60, $T=286300 \mathrm{~s}, \mathrm{X}-\mathrm{Z}$ plane, problem 3-2-15. 


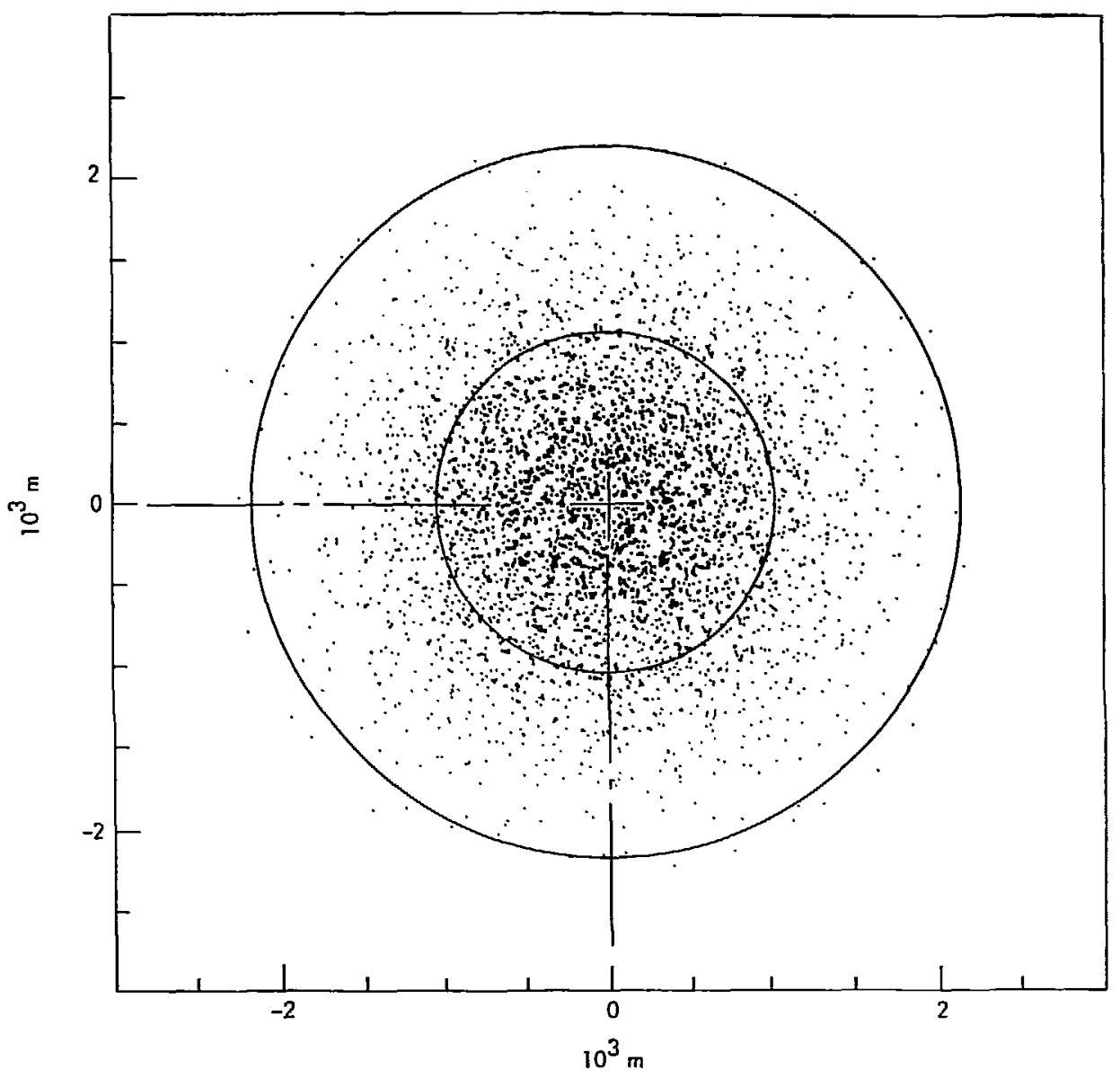

Fig. 5. Particle distribution at Cycle $60, T=236300 \mathrm{~s}, \mathrm{X}-\mathrm{Y}$ plane, problem 3-2-15. Inner circle: concentration $=1 /$ e central concentration. 


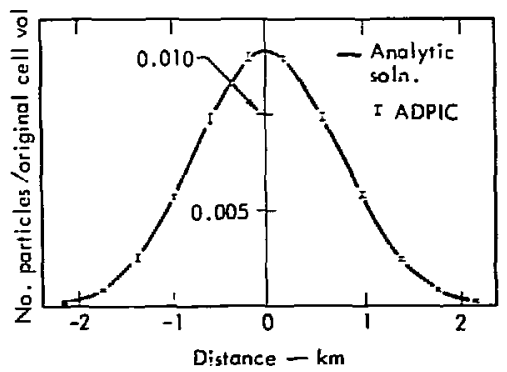

Fig. 6. Plot of particle concentration per original cell volume at cycle $60, x-z$ plane, along the X-axis. Prob.em 3-2-15.

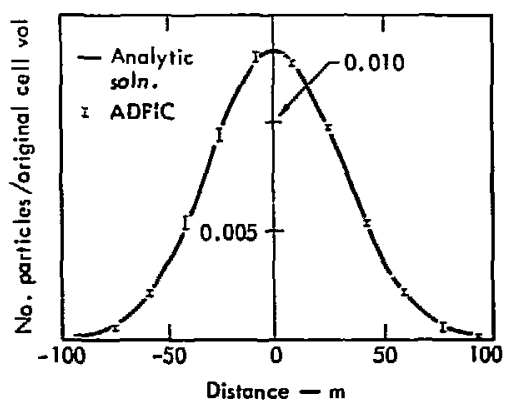

Fig. 7. Plat of particle concentration per original cell volume at cycle $60, x-2$ plane, along the $Z$-axis. Prablem 3-2-15.

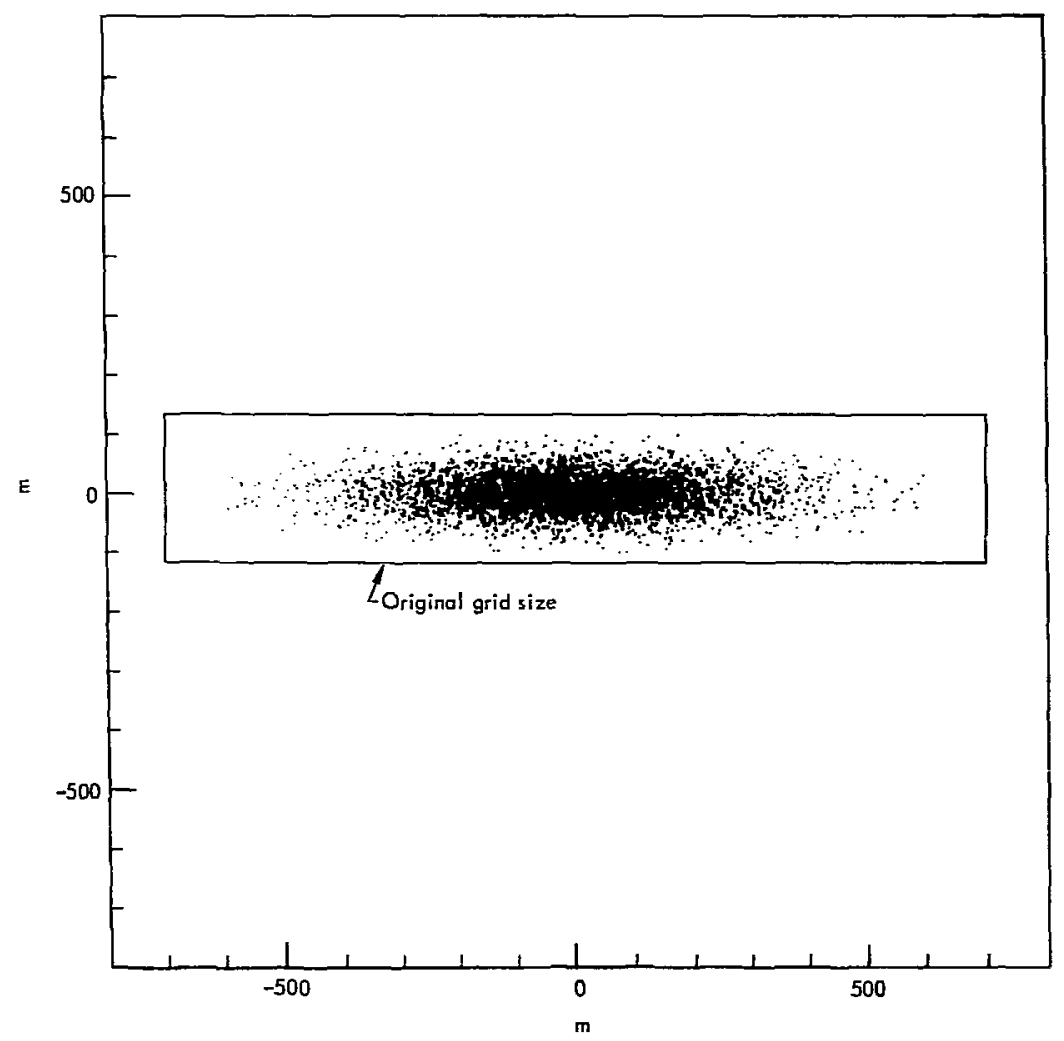

Fig. 8. Initial particle distribution $Y-Z$ plane, problem 3-3-24B. 


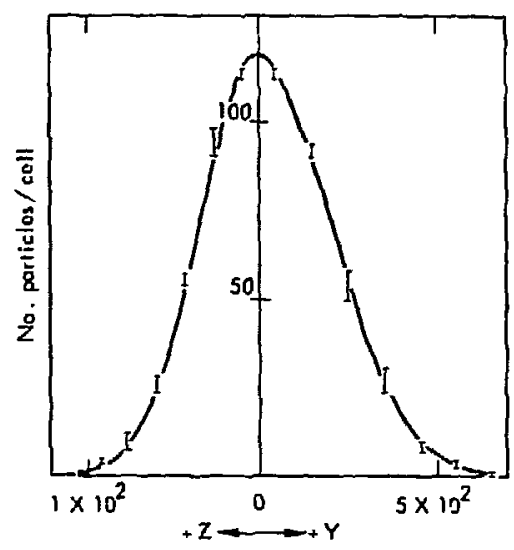

Distonce - $m$

Fig. 9. Initial particle distribution, $Y-Z$ plane, along the $Y$ - and $Z$-axes, problem 3-3-24B.

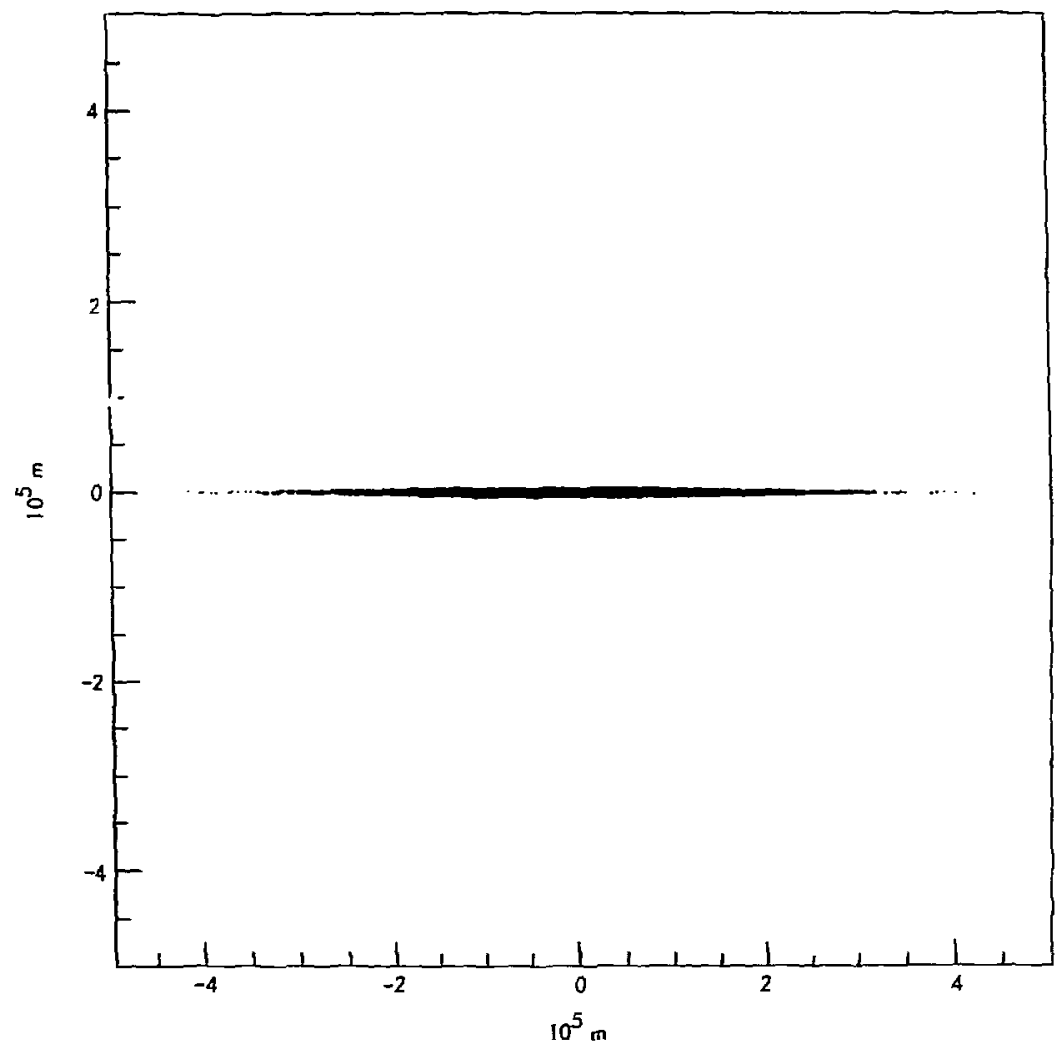

Fig. 10. Particle distribution at Cycle $100, T=88720 \mathrm{~s}, \mathrm{Y}-\mathrm{Z}$ plane, Problem 3-3-24B. 


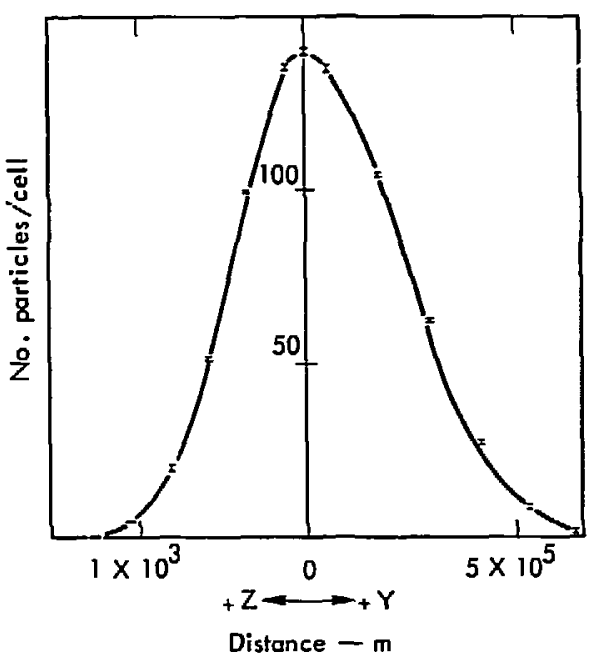

Fig. 11. Plot of particle distribution, $\mathrm{Y}-\mathrm{Z}$ plane, along the $\mathrm{Y}-$ and $\mathrm{Z}-$ axes at Cycle 100, $T=88720 \mathrm{~s}$, problem $3-3-24 B$.

$$
\begin{gathered}
\mu=S a / D, \tau=t D / a^{2}, x^{\prime}=x / a, \\
y^{\prime}=y / a, z^{\prime}=z / a
\end{gathered}
$$

with $a=\sqrt{2 \sigma_{0}}$ ite initial cloud radius in terms of the initial standard deviation of the particle distribution. $D=K_{x x}=K_{y y}$ $=K_{z z}$ are the constant diffusion parameters. $S=(\partial U / \partial z)$ is the shear factor which is introduced into the ADPIC problem via the advection wind field in the $x-z$ plane in the following way:

$$
\mathrm{U}_{\mathrm{A}}=\mathrm{U}_{\mathrm{AO}}+\mathrm{SZ} \text {. }
$$

Letting $U_{A 0}=0$, we obtain a constant shear in the $x-z$ plane with the mean advection defined as zero at the cloud center. To calculate the ADPIC cell concentration $\chi(x, y, z, t)$, we multiply

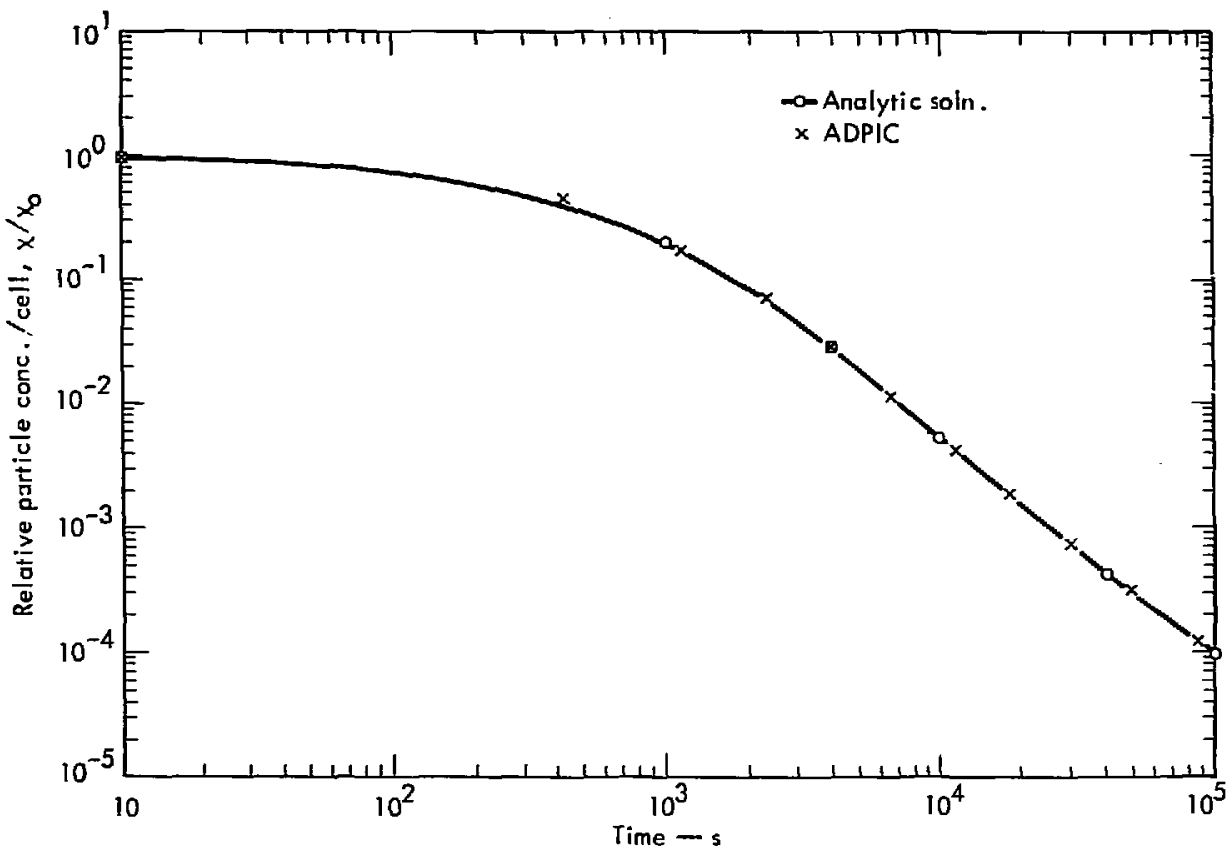

Fig. 12. Plot of relative particle concentration per cell at cloud center versus time. Problem 3-3-24B. 
the analytic solution Eq. (37) through by $X_{0}=Q \cdot \Delta V /\left[0_{0}^{3}(2 \pi)^{3 / 2}\right]$, where $Q$ is the number of particles in the puff and $\Delta V$ is the cell volume.

ADPIC models shear by superimposing the advective velocity field $\vec{U}_{A}$ which contains the shear on the diffusion velocity field $\vec{U}_{D^{*}}$ In this problem, a spherically symmetric Gaussian particle distribution with an initial standard deviation $\sigma_{0}=20 \mathrm{~m}$ was generated at the center of an ADPLC grid mesh of $20 \times 20 \times 20$ cubical cells of cell size $\Delta X=\Delta Y=\Delta Z=7 \mathrm{~m}$. The expanding grid version of ADPIC was used. The simple shear in the $x-z$ plane was introduced with the advection velocity field in the form of Eq. (38) with $S=0.125 \mathrm{sec}^{-1}$. The problem ran to 120 cycles, $T=6328 \mathrm{sec}$ and the diffusion parameters were $K_{x x}=K_{y y}=K_{z z}$ $=10^{6} \mathrm{~cm}^{2} / \mathrm{sec}$. The grid expanded many times, each time by a factor of 1.3 in

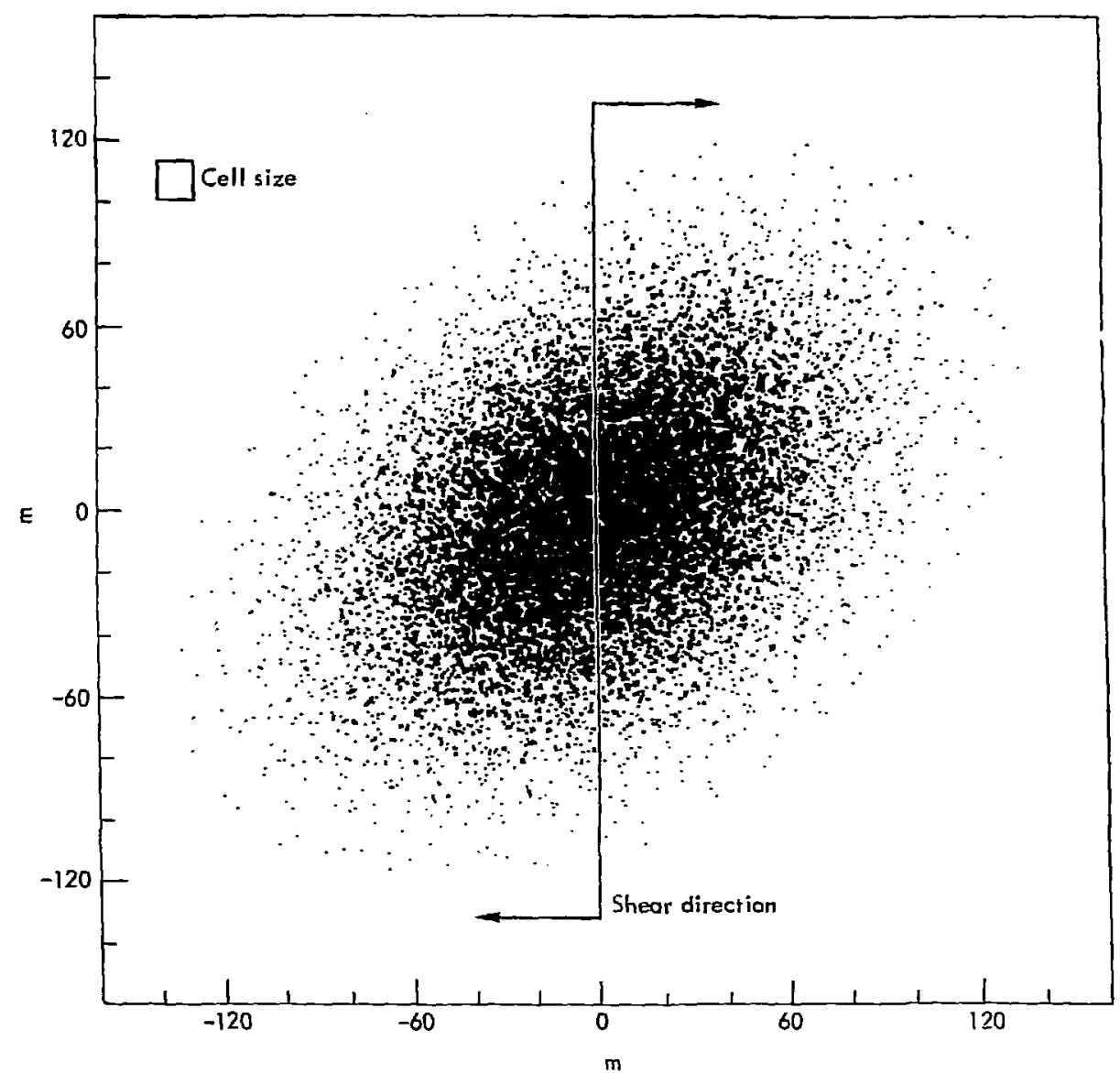

Fig. 13. Particle distribution at cycle 20, $T=5.3 \mathrm{~s}, \mathrm{X}-\mathrm{Z}$ plane, problem 3-3-26. 
the respective coordinate direction until at the last cycle 120, the cell size was $\Delta \mathrm{X}=194500 \mathrm{~m}, \Delta \mathrm{Y}=\Delta \mathrm{Z}=466 \mathrm{~m}$.

Figures 13, 14, 15, 16 and 17 show the ADPIC particle distribution in the $x-z$ plane at various times. Figures 18 and 19 show the particle cell concentrations of ADPIC versus distance in the $\pm x$ and $\pm z$ directions respectively at $T=62.54 \mathrm{sec}$, cycle 50 . The fact that the distributions on the plots are not symmetric with respect to $x=0$ is due to the location of the cell centers nearest the $\mathrm{x}$-axis being $1 / 2 \Delta \mathrm{X}$ away from the axis. Figures 20 and 21 similarly display the cell concentrations at $T=6328 \mathrm{sec}$, cycle 120. Due to the influence of the shear, the resolution of the particle distribution by the grid becomes poorer at late times and ADPIC begins to diffuse

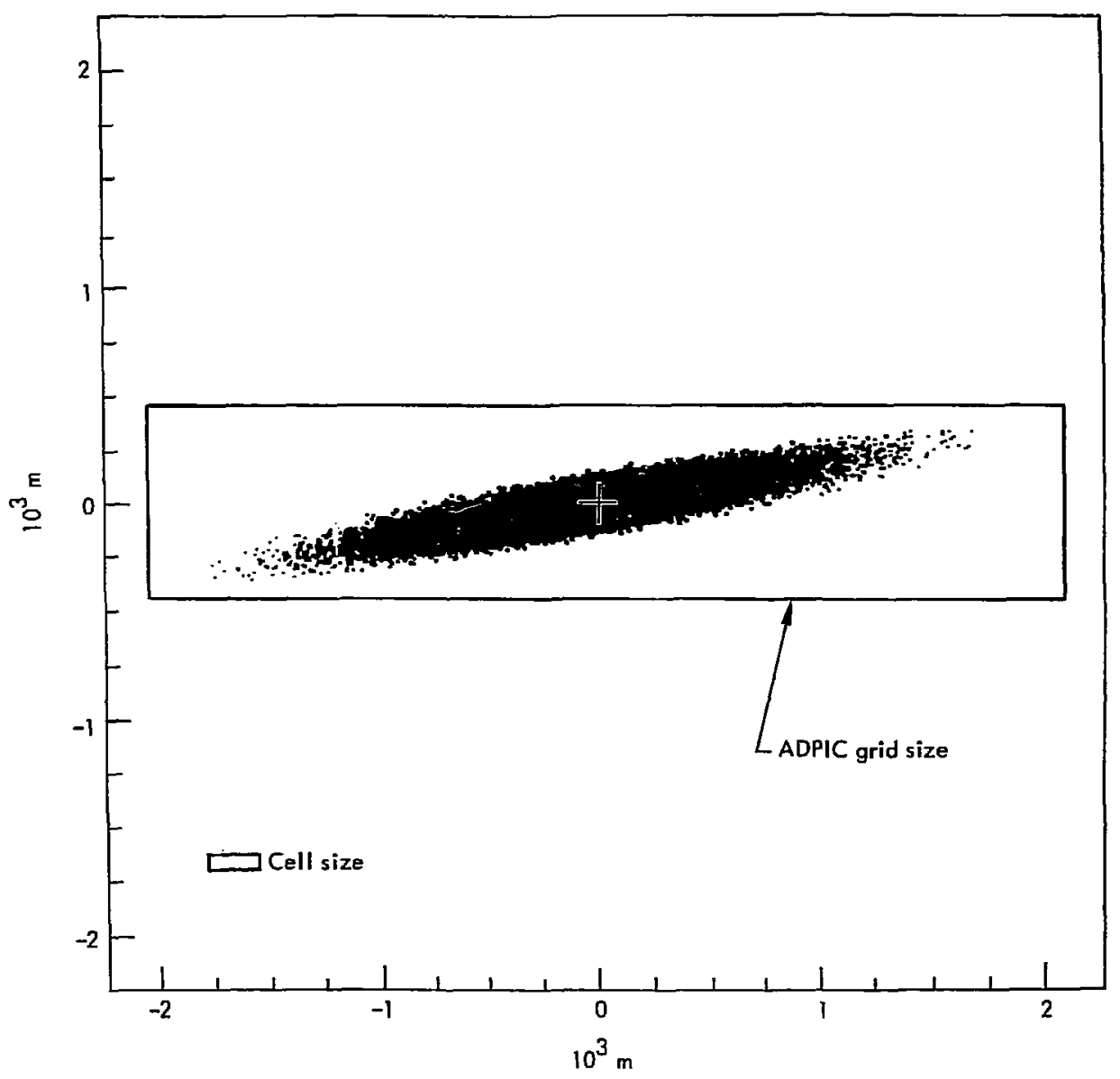

Fig. 14. Particle distribution at cycle 50, $T=62.5 \mathrm{~s}, X-Z$ plane, problem 3-3-26. 


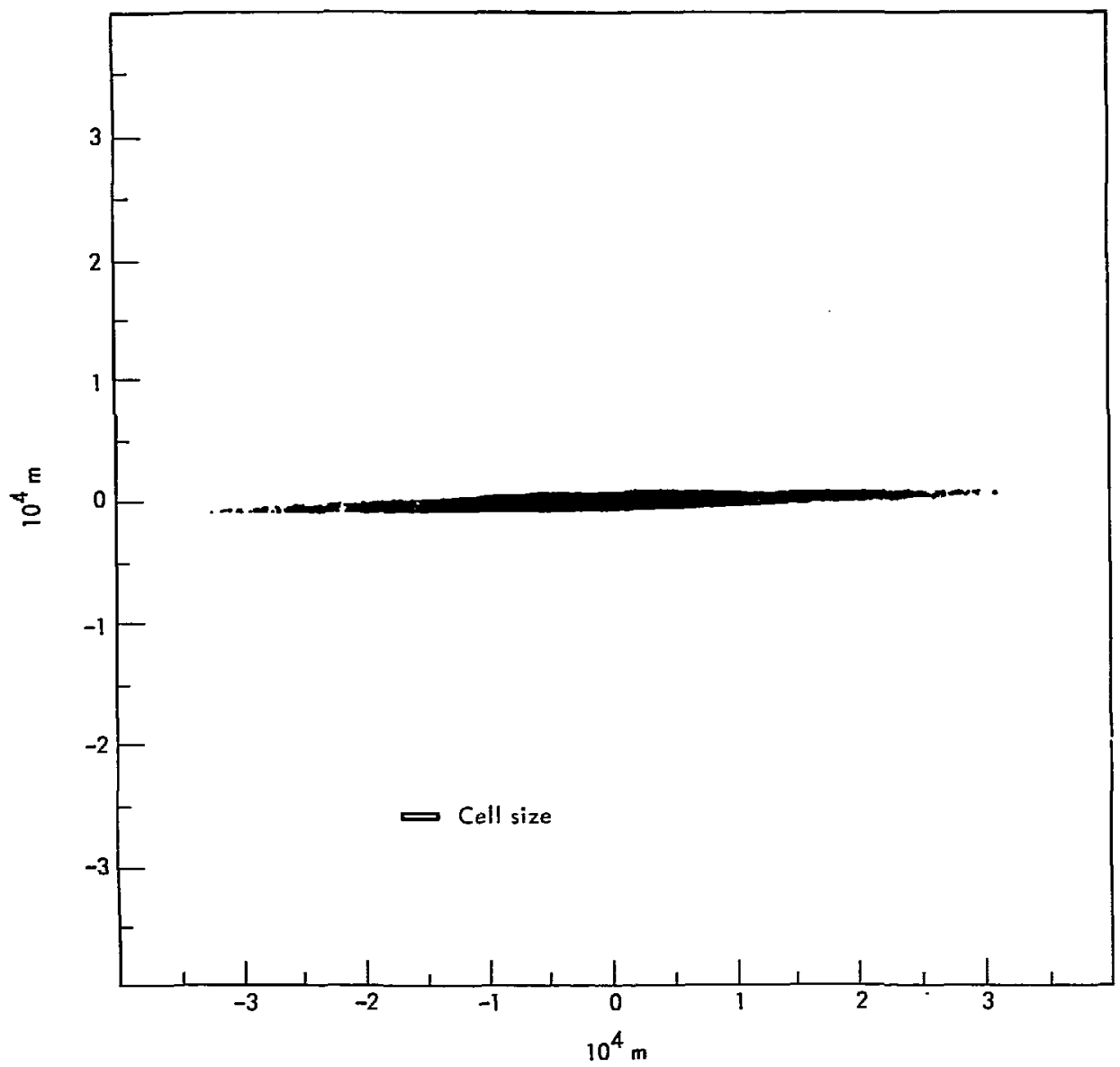

Fig. 15. Particle distribution at cycle $80, T=464 \mathrm{~s}, X-Z$ plane, problem 3-3-26. 


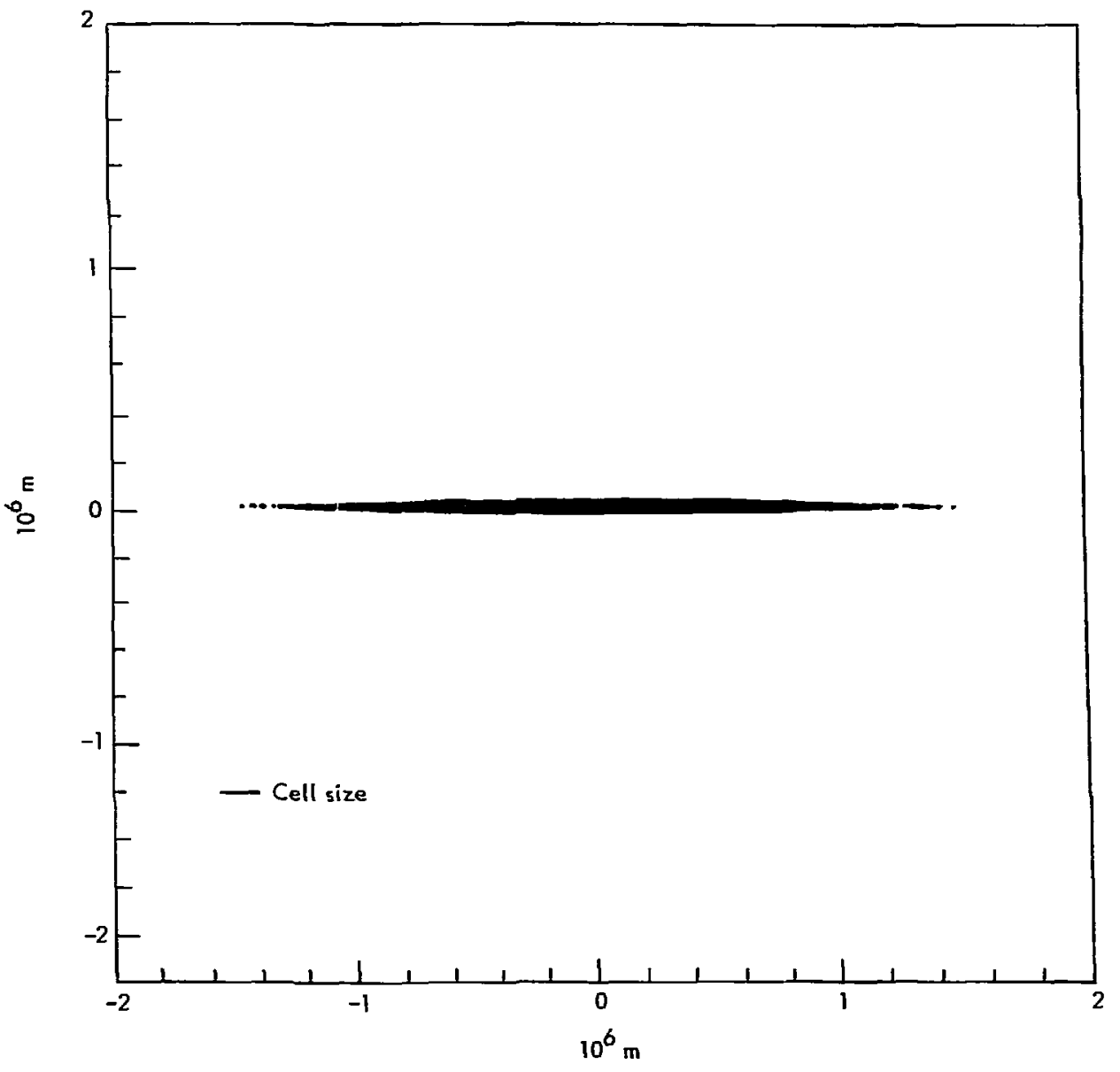

Fig. 16. Particle distribution at cycle $120, T=6328 \mathrm{~s}, \mathrm{X}-\mathrm{Z}$ plane, problem 3-3-26. 


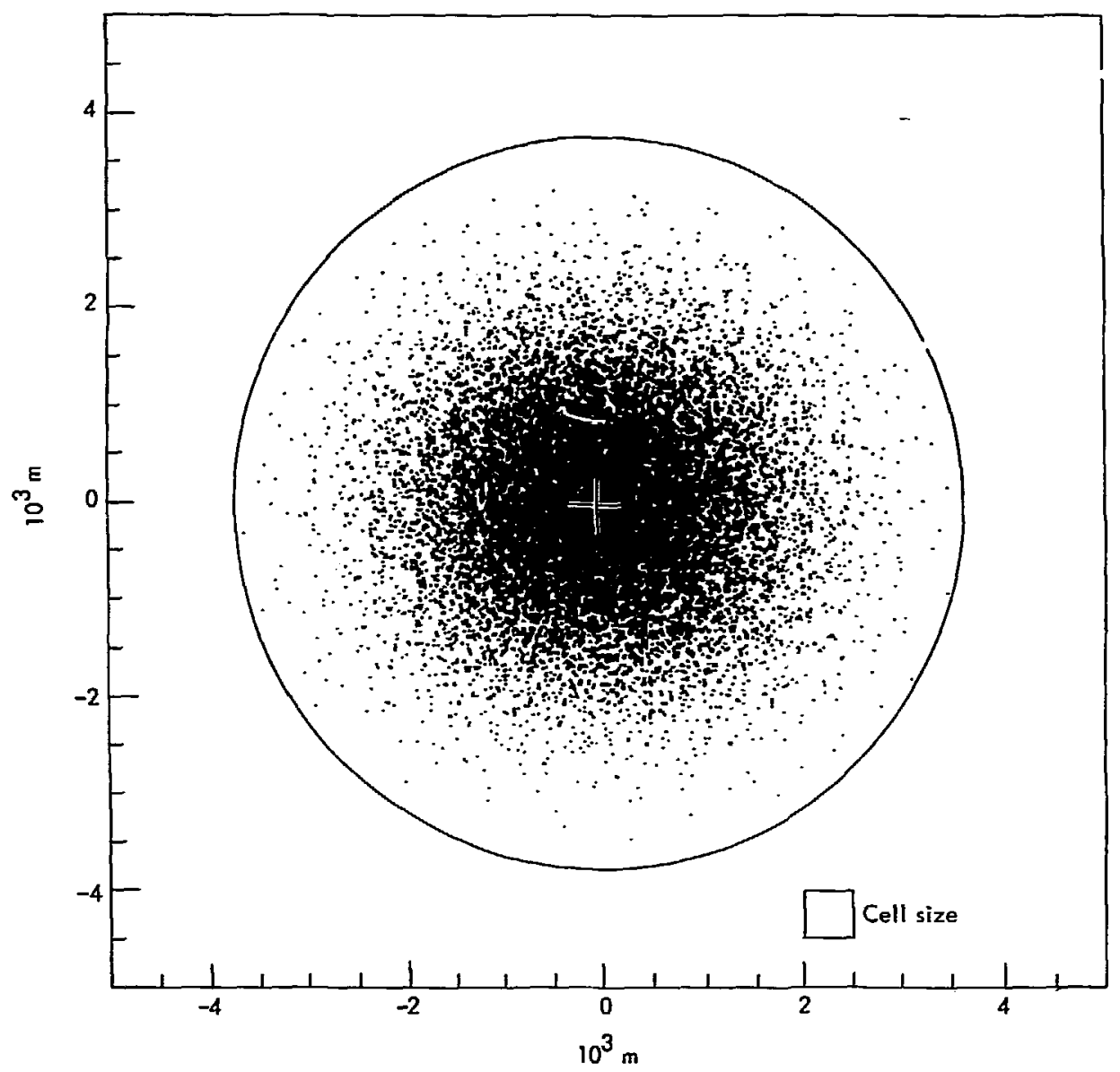

Fig. 17. Particle distribution at cycle 120, $T=6328 \mathrm{~s}, \mathrm{Y}-\mathrm{Z}$ plane, problem 3-3-26. 


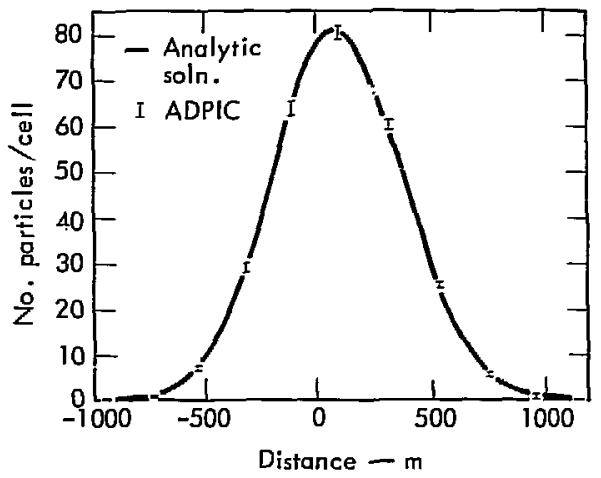

Fig. 18. Plot of particle cell concentration versus distance at cycle 50 , $\mathrm{T}=62.54 \mathrm{~s}, \mathrm{X}-\mathrm{Z}$ plane, along the $X$-axis, problem 3-3-26.

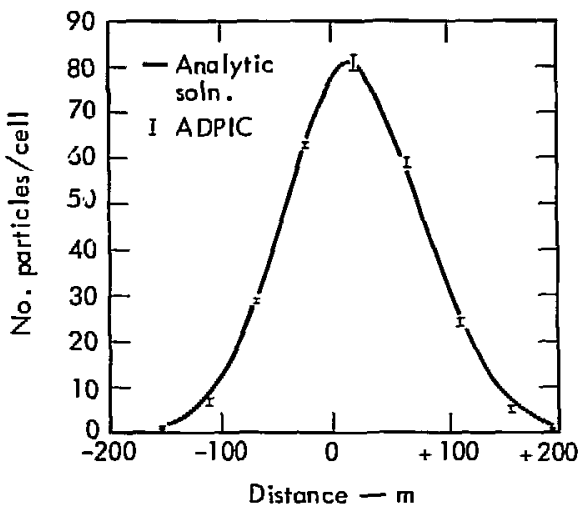

Fig. 19. Plot of particle cell concentration versus distance, cycle 50, $\mathrm{T}=62.54 \mathrm{~s}, \mathrm{X}-\mathrm{Z}$ plane, along the Z-axis, problem 3-3-26.

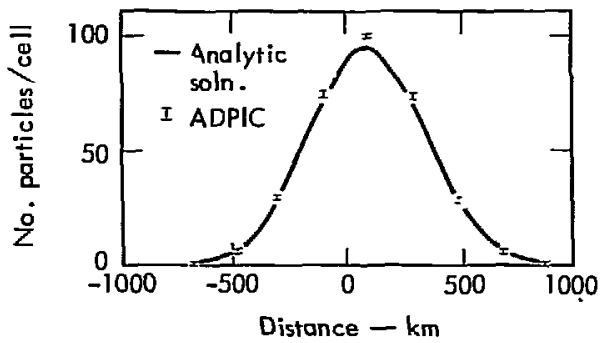

Fig. 20. Plot of particle cell concentration versus distance, cycle 120 , $T=6328 \mathrm{~s}, X-Z$ plane, along the $\mathrm{X}$-axis, problem 3-3-26.

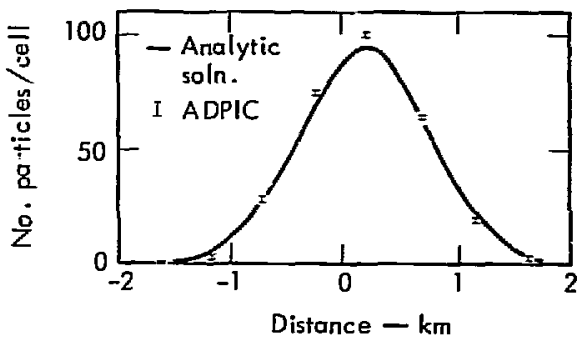

Fig. 21. Plot of particle cell concentration versus distance, cycle 120 , $T=6328 \mathrm{~s}, X-Z$ plane, along the $Z$-axis, problem 3-3-26.

too slowly. The jeginning of this effect can be seen in Figs. 20 and 21. Figure 17 shows an end view looking along the $x$-axis into the $y-z$ plane at late time. No shear is active in this plane and the distribution is circular, as one would expect for a pure diffusion problem. Figure 22 shows the relative puff center concentration as a iunction of time for both the analytic solution and ADPIC.

\section{CONTINUOUS SOURCES (PLUMES)}

\section{General Discussion}

Continuous sources are generated in ADPIC by releasing sequential puffs. The individual puffs are created each time cycle by a special source subroutine that works on the same basis as the one discussed in the section on Particle Generation under Accuracy of ADPIC. The number of particles generated for each puff is governed by the equation:

$$
M^{n}=\frac{\stackrel{Q}{Q} \cdot \Delta T}{P M}
$$

where $M^{n}$ is the number of particles created at cycle $n, \dot{Q}$ is a constant release 


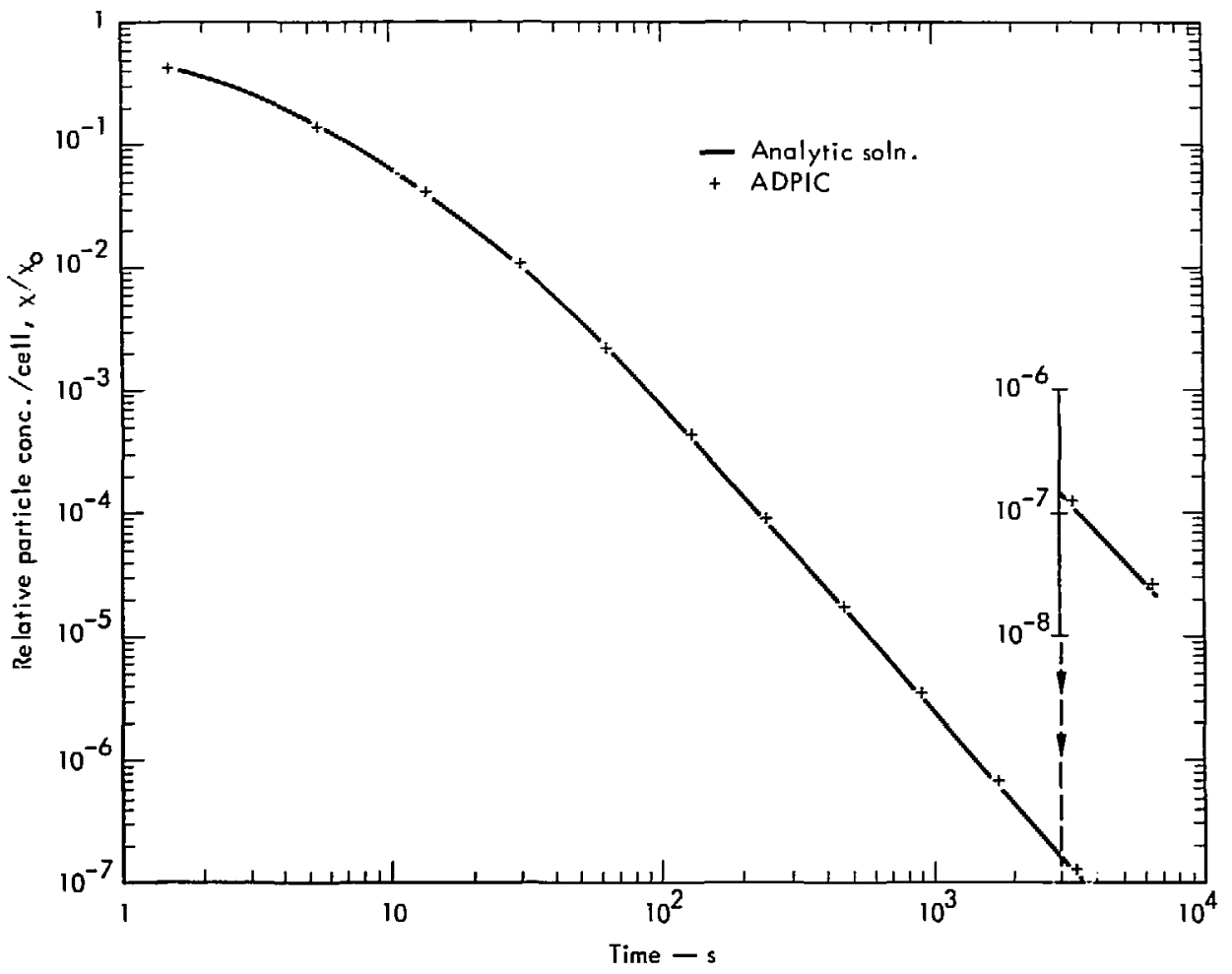

Fig. 22. Relative cloud center concentrations, puff diffusion in simple shear flow, problem 3-3-26.

rate in grams per second (curies per second) and PM is the mass in grams (or activity in curies) per particle, and $\Delta T$ is the ADPIC time step.

The fixed grid mode of ADPIC is appropriate to treat continuous sources because the entire plume length of interest together with topography and meteorology must be covered by the grid mesh. As pointed out in the sections on Accuracy of ADPIC and Scaling for ADPIC, the standard deviation of a source size must be on the order of a grid cell size for the shape of the source distribution to be resolved by the grid mesh, and this represents the major difficulty when near point sources as from stacks are involved. The problem must be solved by first obtaining an extended source from a near point source which then is well resolved for ADPIC. Such an extended source can be obtained in three ways of increasing complexity:

1. An extended source is calculated simply by Gaussian puff diffus:on of the source puffs until the puffs have reached a size that is resolved by the grid mesh and then input into ADEIC. 
2. If the local scale length of diffusion at the position of the particle can be obtained, a diffusivity velocity for that particle can be calculated from this length independent of the ADPIC method, In essence, this implies that the local sub grid scale particle distribution is known for the source particles for which it cannot be obtained by the regular ADPIC method.

3. Finally, the extended source can be obtained by separately computing the close-in problem with ADPIC in which the source is resolved by the grid from the beginning, and the extended source particie distribution thus obtained is used as input to drive the larger scale ADPIC problem.

In all but the simplest cases, Method 1 above will not result in a representative extended source because by the time the source particle distribution has reached the size required, it would have interacted with the topography and have been subjected to time- and space-varying winds.

Method 3 is the most accurate of the three, but also the most cumbersome. Because of time-varying meteorology and due to the statistical nature of the particle generation, it requires that a close-in problem can run for extended source input for every time step of the large-scale ADPIC problem.

Method 2 represents essentially a compromise between 1 and $j$ in that it assumes knowledge of the local sub-grid diffusion scales in terms of the diffusion parameters $\mathrm{K}$ and a Gaussian distribution, but allows the meteorology and topography to interact with the source particles.

This method was adopted to treat sub-grid scale sources in ADPIC, and is discussed in detail in the next section, together with its verification in problems $\mathbf{3}-3-25$ and 3-3-25a.

After that follows the discussion of three problems comparing the results of continuous sources in ADPIC with numerically integrated analytic solutions: Problem 2-3-27 with a continuous source and no advection, essentially the "calm" problem, from a well-resolved source; Problem 2-3-29G continuous source with diffusion and a $2-\mathrm{m} / \mathrm{s}$ advection field and sub-grid scale source; and Problem $2-3-29$ t which is like $2-3-29 \mathrm{G}$ but with a $10-\mathrm{m} / \mathrm{s}$ advection field.

The continuous source problems just mentioned were compared to a numerical time integration of the Gaussian solution of the diffusion-advection equation for the concentration field of successive puffs. Consider a single, spherically symmetric, Gaussian puff of initial size $\sigma_{0}$ and constant diffusivity $K$, released via a constant source rate $Q$ over an infinitesimal time period $d t$ into a constant advection field in the $+x$ direction of magnitude $U(\mathrm{~m} / \mathrm{s})$. The equation for the time rate of change of the concentration field can be written (Ref. 29, P. 267):

$$
\begin{gathered}
d x(x, y, z, t)=\frac{\stackrel{\circ}{Q} d t}{(2 \pi)^{3 / 2}\left(\sigma_{0}^{2}+2 K t\right)^{3 / 2}} \\
\quad x \exp \left\{-\frac{1}{2}\left[\frac{(x-U t)^{2}+y^{2}+z^{2}}{\sigma_{0}^{2}+2 K t}\right]\right\} .
\end{gathered}
$$

When this equation is integrated over infinitely many such puffs in time from 
$\mathrm{t}=0$ to some time $\mathrm{t}=\mathrm{T}$, we obtain the continuous source concentration field $x(x, y, z, t)$ in space and time:

$$
\begin{aligned}
& x(x, y, z, t)=\frac{\dot{Q} \Delta V}{2 \pi^{3 / 2}} \int_{0}^{T} \frac{d t}{\left(\sigma_{0}^{2}+2 K t\right)^{3 / 2}} \\
& x \exp \left\{-\frac{1}{2}\left[\frac{(x-U t)^{2}+y^{2}+z^{2}}{\sigma_{0}^{2}+2 K t}\right]\right\}
\end{aligned}
$$

where the equation has been multiplied through by the ADPIC cell volume $\Delta V$ to obtain $X$ in units of particles per cell. This integral, Eq. (41), was programmed and numerically integrated on the computer to an accuracy of 0.0001 particles/cell and the solution was used to compare with cell concentrations computed by ADPIC at selected points in space and time.

\section{Sub-grid Scale Source Particle Treatment}

As shown in the section Accuracy of ADPIC, when the particle distribution in ADPIC cannot be resolved by the grid mesh, errors in diffusion rates occur. This situation is found when one tries to model continuous sources that are considerably smaller than a cell volume. (The difficulty does not arise in the case of instantaneous sources, as these can be run on the expanding grid version and be well resolved from the beginning.) For such continuous sources in the presence of advection the problem is compounded because the larger the advection, the further the errors of the initially poor resolution of the source particle distribution are carried downwind.

If an assumption can be made about the shape of the source particle distribution at early times until the distribution has spread out enough to represent an extended source, resolved by the grid mesh, the source particles can be diffused in accordance with such a distribution until such time. It should be kept in mind that the only purpose of this source particle treatment is to provide ADPIC with reasonably representative extended source for the study of larger-scale three-dimensional phenomena like varying meteorology, diffusion parameters and topography over distances of hundreds of kilometers, the effect of which are not very sensitive to the exact shape of the source. If effects near the source are to be investigated, the close-in ADPIC problem will have to be run separately. With this in mind, let us assume the sub-grid scale source is Gaussian in character and that it remains locally Gaussian until its standard deviation $\sigma$ is approximately equal to the size of a grid cell and represents an extended source. At this point, the locally Gaussian assumption is discarded and ADPIC calculates diffusion by its concentration gradient method. It will now be shown how this assumption leads to a sub-grid scale diffusivity velocity and how this velocity is integrated to diffuse source particles. This approach treats horizontal and vertical diffusion of the particles independently. For simplicity, the case for the one-dimensional $Y$ direction is illustrated.

For a Gaussian distribution, the concentration field for a puff is described by

$$
x=\frac{Q}{(2 \pi)^{1 / 2} \sigma_{y}} \exp \left(-\frac{1}{2} \frac{y_{D}^{2}}{\sigma_{y}^{2}}\right)
$$

where $x$ is the particle concentration, $Q$ 
the source, $\sigma_{\mathrm{y}}$ the standard deviation and ${ }^{\prime} \mathrm{D}$ the distance of the particle from the center of the distribution. From the definition of the diffusion flux

$$
x V_{D}=-K_{y} \frac{\partial x}{\partial y}
$$

we can, by dividing through by $x$, obtain the definition of diffusion velocity

$$
V_{D}=-\frac{K_{y}}{x} \frac{\partial x}{\partial y}=-K_{y} \frac{\partial(\ln x)}{\partial y}
$$

where $V_{D}$ is an average diffusion velocity and $\mathrm{K}_{\mathrm{y}}$ the diffusion parameter. Calculating $\ln x$ from Eq. (42) and substituting in (44), we obtain for the diffusivity velocity

$V_{D}=-K_{y} \frac{\partial}{\partial y}\left[\ln \frac{Q}{(2 \pi)^{1 / 2}}-\ln \sigma_{y}-\frac{1}{2} \frac{y_{D}^{2}}{\sigma_{y}^{2}}\right]$

$$
=\frac{K y^{y} D}{\sigma_{y}^{2}} .
$$

From the earlier discussion on scaledependent diffusion, we have the two equations

$$
\begin{aligned}
& K_{y}=\epsilon^{1 / 3} \sigma_{y}^{4 / 3} \\
& \sigma^{2}=\left(\sigma_{0}^{2 / 3}+\frac{2}{3} \epsilon^{1 / 3} t\right)^{3}
\end{aligned}
$$

where $C$ has been set equal to 1.

Substituting these into the equation for $v_{D^{\prime}}$ Eq. (45), we obtain after some algebra

$$
\mathrm{v}_{\mathrm{D}}=\frac{\mathrm{y}_{\mathrm{D}}}{\left(\frac{\sigma_{0}^{2}}{\epsilon}\right)^{1 / 3}+\frac{2}{3} t}
$$

This diffusivity velocity is independent of the ADPIC grid mesh and is the desired one defined at the coordinate $\left(y_{D}, t\right)$ of a given source particle. It is important to point out that $\mathrm{y}_{D}$ here is the absolute value of the distance from the particle to the diffusion center as can be seen from its definition in Eq. (42). This "diffusion distance" $g_{D}$ coincides with the actual $y$-coordinate of the particle position in ADPIC only when the origin in ADPIC is the same as the diffusion center and in the absence of advection or buoyancy terms. Similarly, t represents here the "age" of the particle since its creation and $t$ coincides with the actual ADPIC problem time only in the case of a single puff source.

Study of Eq. (46) shows that in the case of a true point source, when $\sigma_{0} \rightarrow 0$, or at late time when $\left(\sigma_{0}^{2}\right)^{1 / 3} \ll \frac{2}{3}$ t for any size source,

$$
V_{D}=\frac{y_{D}}{\frac{2}{3} t}
$$

Hence it is a property of a Gaussian distribution that all those particles for which the diffusion distance $g_{D}$ divided by the diffusion time $t$ is a constant ratio will have the same diffusion velacity $v_{D^{*}}$ Also, Eq. (46) shows that if a particle gets generated as part of a Gaussian source distribution of size $\sigma_{0}$ at a distance $y_{0 D}$ at $t=0$, its initial diffusion velocity is

$$
v_{D}=\frac{y_{0}}{\left(\sigma_{0}^{2} / \epsilon\right)^{1 / 3}}
$$

For the case of cons' nt K, Eqs. (33) and (32) become respectively 


$$
\begin{aligned}
& K=K_{\text {constant }} \\
& \sigma^{2}=\sigma_{0}^{2}+2 \mathrm{Kt} .
\end{aligned}
$$

In parallel development as for the scaledependent case, we obtain then an expression for the diffusivity velocity

$$
\mathrm{V}_{\mathrm{D}}=\frac{\mathrm{y}_{\mathrm{D}}}{\frac{\sigma_{0}^{2}}{\mathrm{~K}}+2 \mathrm{t}}
$$

The validity of Eq. (51) above, under the assumptions made, is shown by two ADPIC calculations at the end of this chapter.

Since also

$$
v_{D}=\frac{\partial y_{D}}{\partial t}
$$

Eq. (51) can be integrated in time since neither $\epsilon, \sigma_{0}$ nor $K$ are here functions of $y$ or t. This integration is carried out each ADPIC cycle over the applicable time step $\Delta t$. From Eqs. (51) and (52) for the constant $K$ case, the integral equation is

$$
\int_{y_{D}}^{y_{D}+\Delta y^{2}} \frac{d y_{D}}{y_{D}}=\int_{t}^{t+\Delta t} \frac{d t}{\frac{\sigma_{0}^{2}}{K}+2 t} .
$$

Integrating (53) and solving for $\Delta \mathrm{y}_{\mathrm{D}^{\prime}}$

$$
\Delta y_{D}=y_{D}\left\{\left[1+\frac{\Delta t}{\left(\sigma_{0}^{2} / 2 K\right)+t}\right]^{1 / 2}-1\right\}
$$

where $\Delta y_{D}$ is the distance diffused by the source particle during time step $\Delta t$, $y_{D}$ is the diffusion distance at the begin- ning of the cycle, $\Delta t$ is the ADPIC time step and $t$ is the "age" of the source particle at the beginning of the cycle.

A similar integration of Eq. (46) for the scale-dependent diffusion case results in

$$
\Delta y_{D}=y_{D}\left\{\left[1+\frac{\Delta t}{\frac{3}{2}\left(\frac{\sigma_{0}^{2}}{\epsilon}\right)^{1 / 3}+t}\right]^{3 / 2}-1\right\} .
$$

The actual distance traveled by a source particle during one cycle in the ADPIC grid can now be computed by adding the distance $\Delta \mathbf{y}_{\mathbf{A}}$ from advection to the distance $\Delta y_{D}$ diffused during a time step:

$\Delta y=\Delta y_{D}+\Delta y_{A}=\Delta y_{D}+V_{A} \cdot \Delta t$

where $\mathrm{V}_{\mathrm{A}}$ is the weighted advection velocity obtained in the same way as for regular non-source ADPIC particles.

The various updated values at cycle $n+1$, the actual source particle coordinate in ADPIC $y$, the diffusion distance $y_{D}$ and the particle age $t$ are then calculated and stored for each individual source particle for the next cycle, i.e.,

$$
\begin{aligned}
& y^{n+1}=y^{n}+\Delta y \\
& y_{D}^{n+1}=y_{D}^{n}+\Delta y_{d} \\
& t^{n+1}=t^{n}+\Delta t .
\end{aligned}
$$

For continuous sources, sets of Gaussian distributions of size $\sigma_{0}$ of source particles are generated as discussed earlier. All those particles generated during the same 
cycle will have a variety of initial diffusion distances $y_{D}$ according to the Gaussian distribution, but all will have the same initial age, namely $t=0$. After one cycle of diffusion in the manner discussed above, their age will be $t=\Delta t_{1}$ where $\Delta t_{1}$ is the ADPIC time step, and after two cycles $t=\Delta t_{1}+\Delta t_{2}$ and so on. So at any one time there will exist several sets of source particles, each set of different age. When a given set of source particles that started out with a standard deviation $\sigma_{0}$ representative of the source size has diffused to a distribution size with a standard deviation $\sigma \approx \Delta Y$ where $\triangle Y$ is the ADPIC cell length, the whole set is considered a suitable extended source and is released from its source particle status and is considered to consist of regular ADPIC particles. The test for release is made against $t$, the particle-set age at every time step. In the meantime, source particles are subject to the same boundary conditions as regular particles, with deposition on tive topography being one of the most important, to provide a reasonable extended source. While the source particles are treated independent of regular ADPIC particles as a sub-grid scale distribution, they are counted together with the regular particles in determining the particle concentration field in ADPIC which is used to calculate the diffusion velocities for the regular particles.

The special source diffusivity velocity for the constant $\mathrm{K}$ case, Eq. (51), was tested on ADPIC for its validity with two problems. This was accomplished by replacing in the code the expression for calculating the diffusion velocity in the $y$-direction,

$$
V_{D}=-\frac{K}{\bar{x}} \frac{\Delta x}{\Delta Y}
$$

by the special prescription, Eq. (51),

$$
V_{D}=\frac{{ }^{y} D}{\frac{\sigma_{0}^{2}}{K}+2 t}
$$

and similarly for the other two velocity components $U_{D}$ and $W_{D}$ in the $x-$ and z-directions, thereby making ADPIC particles special source particles for the duration of the entire problem."

A 4000-particle single release with a spherically symmetric Gaussian distribution of $\sigma_{0}=2 \Delta Y$ was generated in a

\footnotetext{
"It can be shown analytically that (59) and (51) ar - equivalent in the lim it of $\left[\frac{1}{2} \frac{y_{D} \Delta Y}{\left(\sigma_{0}^{2}+2 \mathrm{Kt}\right)}\right]^{3}$ and $\frac{\Delta Y^{2}}{2\left(\sigma_{0}^{2}+2 \mathrm{Kt}\right)}$ both being $\ll 1$, by substituting $\Delta x=\frac{Q}{(2 \pi)^{1 / 2}} \frac{1}{\left(\sigma_{0}^{2}+2 \mathrm{Kt}\right)^{1 / 2}}\left\{\exp \left[-\frac{\left(\mathrm{y}_{\mathrm{D}}+\Delta \mathrm{Y}\right)^{2}}{2\left(\sigma_{0}^{2}+2 \mathrm{Kt}\right)}\right]-\exp \left[-\frac{1}{2} \frac{\mathrm{y}_{\mathrm{D}}}{\left(\sigma_{0}^{2}+2 \mathrm{Kt}\right)}\right]\right\}$ and $\bar{x}=\frac{Q}{(2 \pi)^{1 / 2}} \frac{1}{\left(\sigma_{0}^{2}+2 \mathrm{Kt}\right)^{1 / 2}} \exp \left[-\frac{\left(\mathrm{y}_{\mathrm{D}}+\frac{1}{2} \Delta \mathrm{Y}\right)^{2}}{2\left(\sigma_{0}^{2}+2 \mathrm{Kt}\right)}\right]$ into Eq. (59) above. 


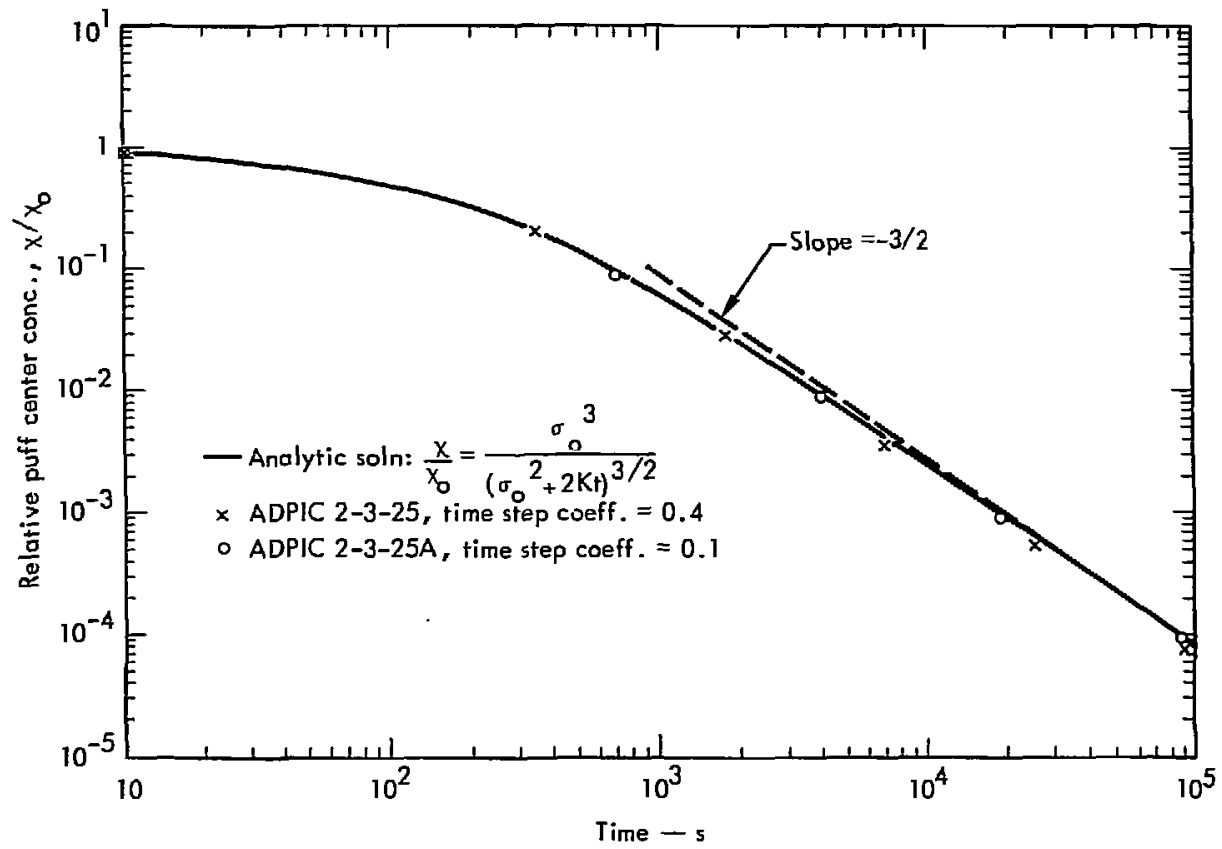

Fig. 23. Relative puff center concentration for a source particle puff, problem 3-3-25 and $3-3-25 A$.

cubical $14 \times 14 \times 14$ cell ADPIC grid and left to diffuse according to Eq. (51). The initial cell size was $\Delta X=\Delta Y=\Delta Z=10 \mathrm{~m}$. The diffusion parameter was $\mathrm{K}=10^{4} \mathrm{~cm}^{2} / \mathrm{s}$.

Problem 3-3-25 used a time-step coefficient $F=0.4$ in the time-step calculation,

$$
\Delta t=F \cdot \frac{\Delta Y}{\left|V_{D}\right| \text { MAX }} .
$$

while problem 3-3-25A used an $F=0.1$. Figure 23 shows the relative puff center concentrations as a function of time for both problems and for the analytic solution. The problem with the larger timestep coefficient diffuses a little too fast which is to be expected in the light of the time-step discussion in the section, Time-Step Calculation.

When $\sigma_{0}^{2} \ll 2 \mathrm{Kt}$, at late times,

$$
\frac{x}{x_{0}} \propto t^{-3 / 2} .
$$

This corresponds to a slope of $-3 / 2$ on $\log$-log paper, and is plotted for comparison with the late-time ADPIC solutions in Fig. 23.

Continuous Source: Diffusion Only (Calm Condition)

Problem 2-3-27 was run to compare ADPIC results with the numerically integrated analytic expression, Eq. (41), discussed previously, for the case of a continuous succession of spherically 
symmetric Gaussian source puffs of size $\sigma_{0}$ released each cycle into a fixed ADPIC grid of $28 \times 28 \times 14$ cubical cells and $L=f t$ to diffuse. The ADPIC cell size is $1000 \mathrm{~m}$ in the $\mathrm{x}, \mathrm{y}$, and $\mathrm{z}$ directions, $\tau_{0}=2 \Delta X=2000 \mathrm{~m}$, i.e., the size of the suurce is well resolved by the grid mesh and special source particles are not used. Advection $\mathrm{U}_{\mathrm{A}}=\mathrm{V}_{\mathrm{A}}=\mathrm{W}_{\mathrm{A}}=0$. The diffusion parameters $\mathrm{K}_{\mathrm{x}}=\mathrm{K}_{\mathrm{y}}=\mathrm{K}_{\mathrm{z}}=10^{7} \mathrm{~cm}^{2} / \mathrm{s}$.
The problem ran for 100 cycles to $42450 \mathrm{~s}$. The total number of particles generated was 21222 , giving an average number of 212.22 particles generated per cycle. A total of 5772 particles left the grid through the boundary, leaving 15550 particles in the problem at the end. Figures $24,25,26$ and 27 show the cathoderay-tube display of the particle distribution at various times. Figure 28 compares

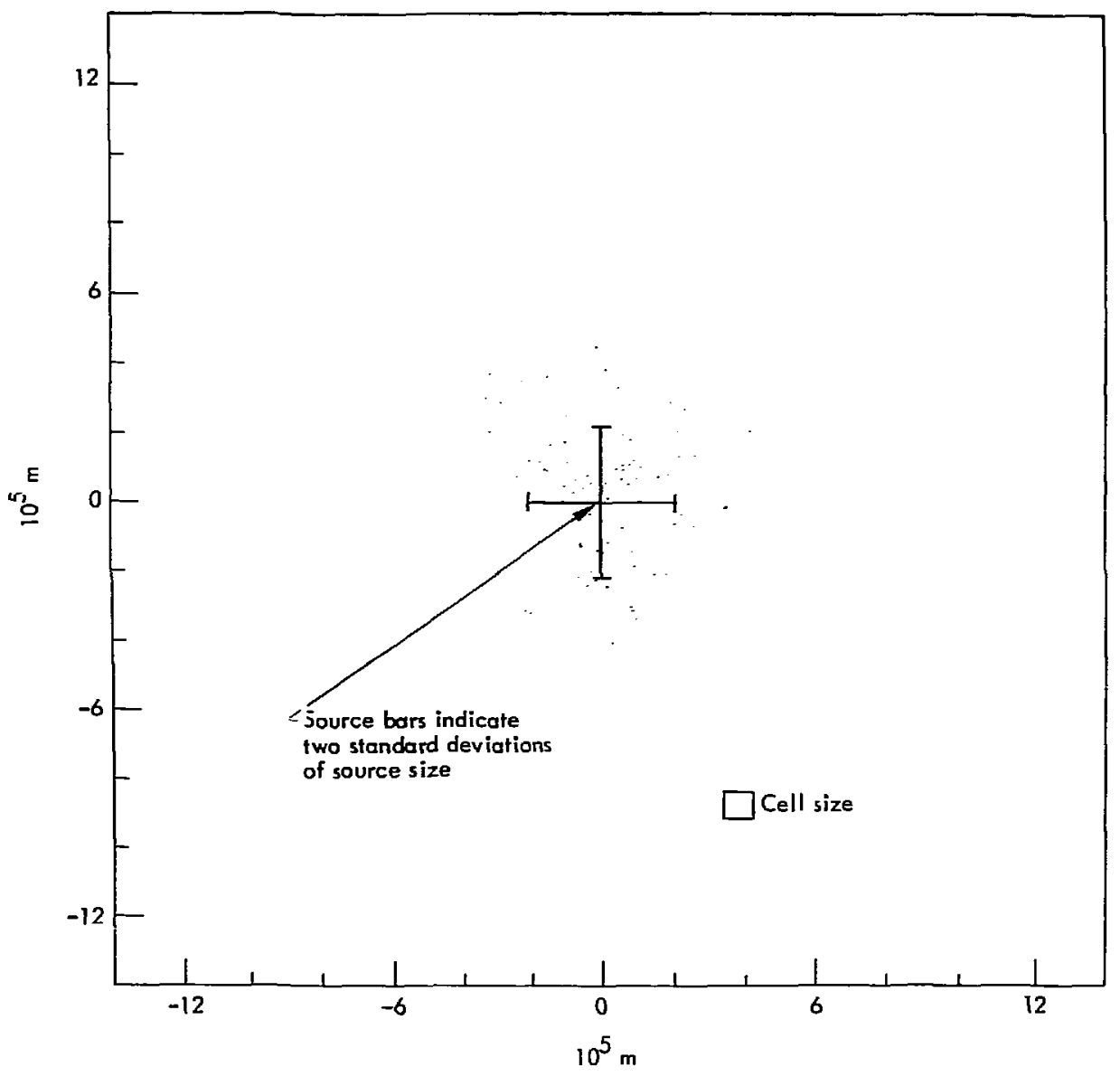

Fig. 24. Initial particle distribution, $X-Y$ plane, continuous source, diffusion only, problem 2-3-27. Source bars indicate two standard deviations of source size. 


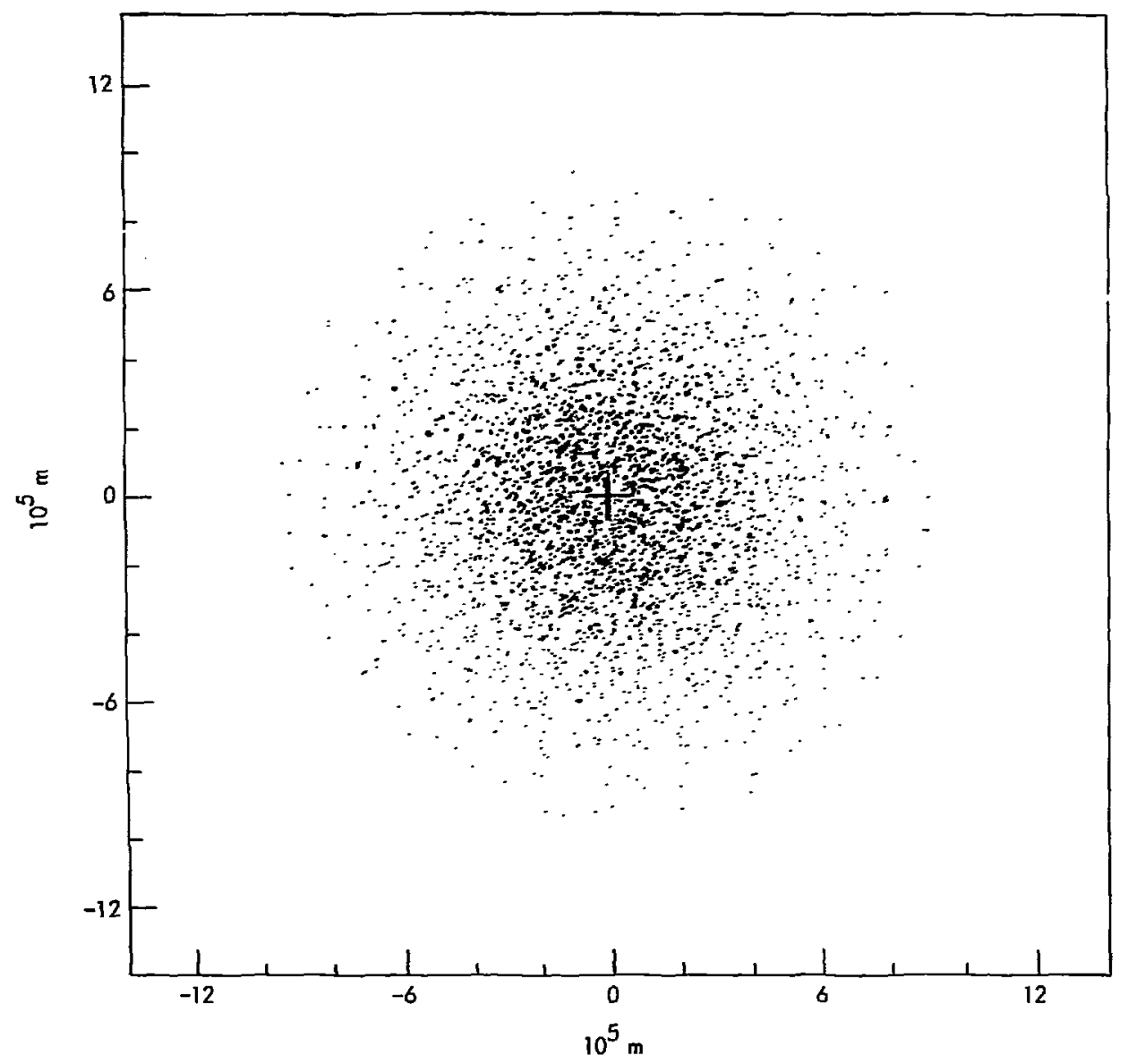

Fig. 25. Particle distribution at cycle 20, $T=8234$ 5, X-Y plane, problem 2-3-27. 


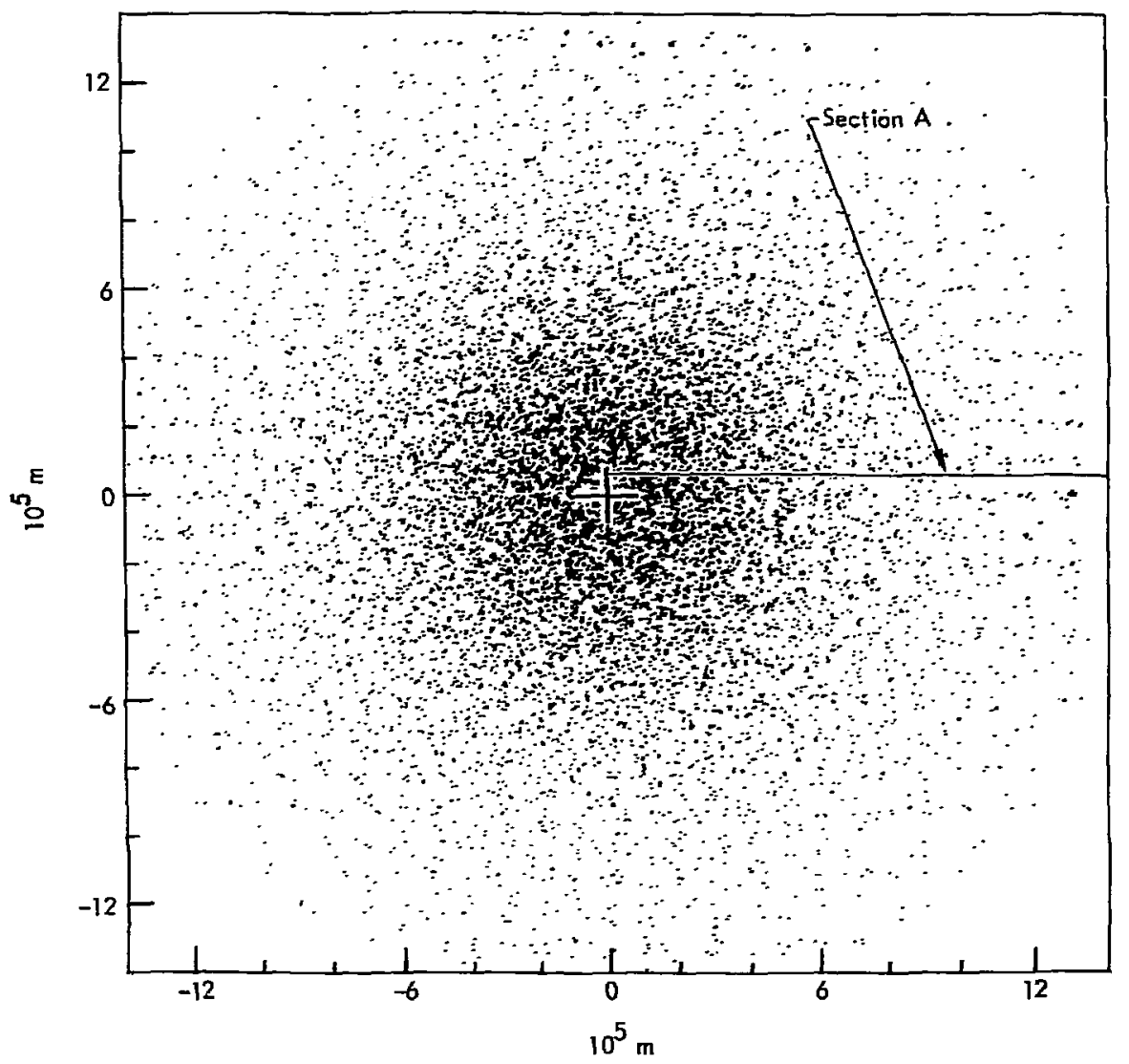

Fig. 26. Particle distribution at cycle $60, \mathrm{~T}=24830 \mathrm{~s}, \mathrm{X}-\mathrm{Y}$ plane, problem 2-3-27. 


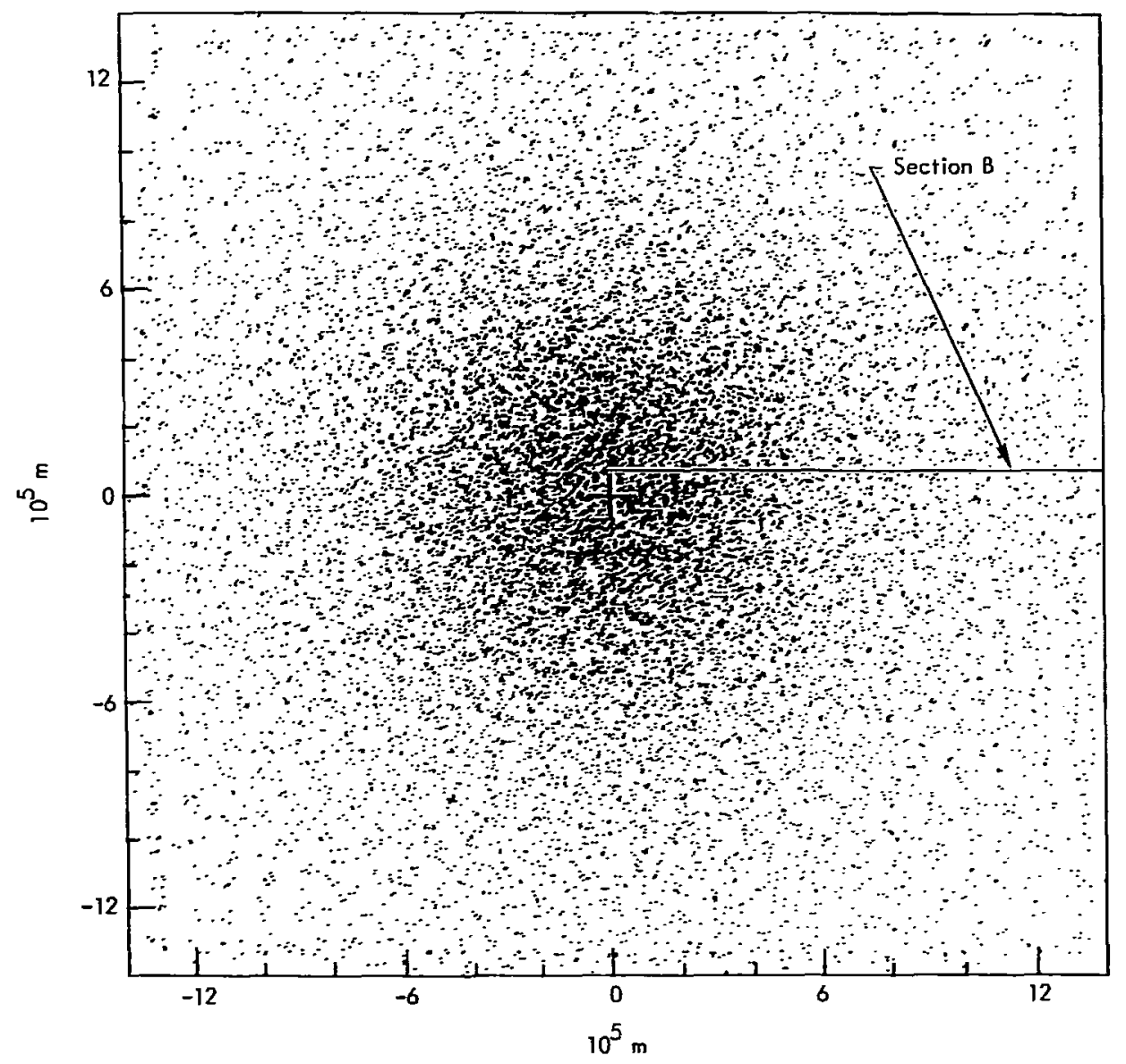

Fig. 27. Particle distribution at cycle 100, $T=42450 \mathrm{~s}, \mathrm{X}-\mathrm{Y}$ plane, problem 2-3-27. 


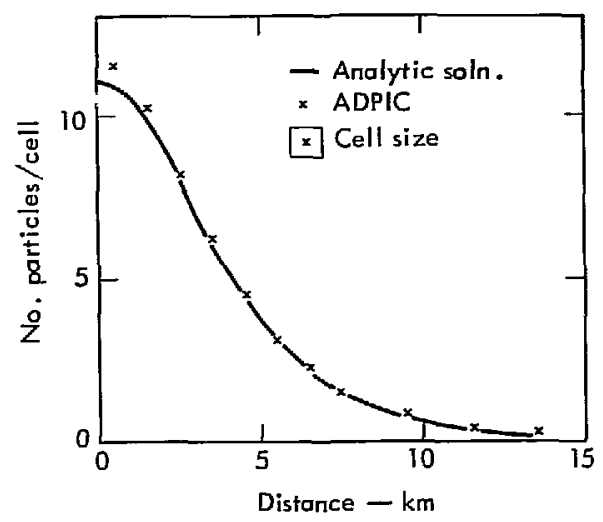

Fig. 28. Plot cell center concentrations along section A, Fig. 26. Continuous source: Diffusion only, problem 2-3-27.

the analytic solution and the ADPIC solution in terms of number of particles per cell (defined at cell centers in ADPIC) versus distance along section $A$ as located in Fig. 26. Similarly, Fig. 29 shows the ADPIC versus analytical solution comparison for a section indicated in Fig. 27 .

Continuous Source: Diffusion and Advection

Problems 2-3-29G was run to compare the results of ADPIC with the num erically integrated expression, Eq. (41), for the case of a continuous succession of spherically symmetric Gaussian source puffs of size $\sigma_{0}$ released each cycle into the fixed ADPIC grid of $28 \times 28 \times 14$ cubical cells and subjected to diffusion and a constant advection velocity in the $+X$ direction of $U_{A}=2 \mathrm{~m} / \mathrm{s}$. Each cell was $1000 \mathrm{~m}$ in the $\mathrm{x}, \mathrm{y}$, and $\mathrm{z}$ directions. The size of the source is $\sigma_{0}=20 \mathrm{~m}$, hence is not resolved by the ADPIC grid, and the special source particle treatment

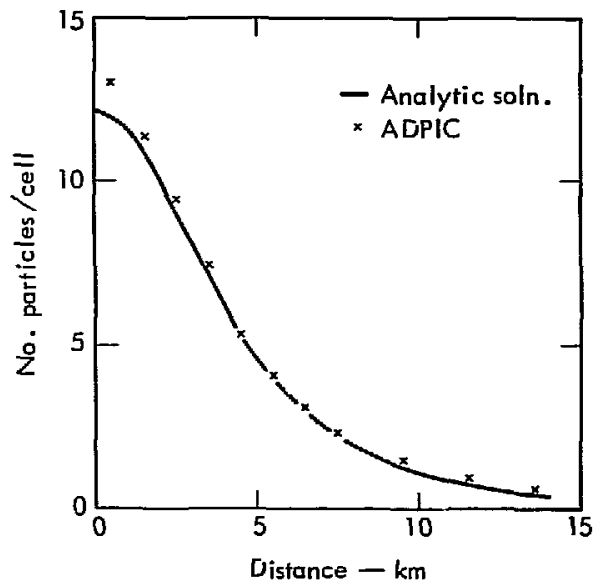

Fig. 29. Plot of cell concentrations along section B, Fig. 27. Continuous source: Diffusion only.

discussed in the section on Instantaneous Source Diffusion with Constant $K$, is employed. The diffusion parameters are $\mathrm{K}_{\mathrm{x}}=\mathrm{K}_{\mathrm{y}}=\mathrm{K}_{\mathrm{z}}=10^{7} \mathrm{~cm}^{2} / \mathrm{s}$. The problem ran for 167 cycles and $23470 \mathrm{~s}$ and the total number of particles generated was 23472 , giving an average of 140.5 particles generated per cycle. A total of 12371 particles left the grid due to advection and diffusion, leaving 11413 particles still in the problem at the end. The number of particles lost per cycle and particles generated at the source per cycle became equal at cycle $126, \mathrm{~T}=1733 \mathrm{c} \mathrm{s}$, indicating that the plume had reached a steady state. Figures 30, 31, 32 and 33 show the CRT display of the particle distribution in the $x-y$ plane at various times. Figures 34 and 35 show comparisons between ADPIC concentrations and the analytic solution along sections $A$ and $B$ whose locations are indicated in Fig. 31 . Figures 36 and 37 show the same comparisons at late times along sections $C$ and $D$, as located in Fig. 33. 


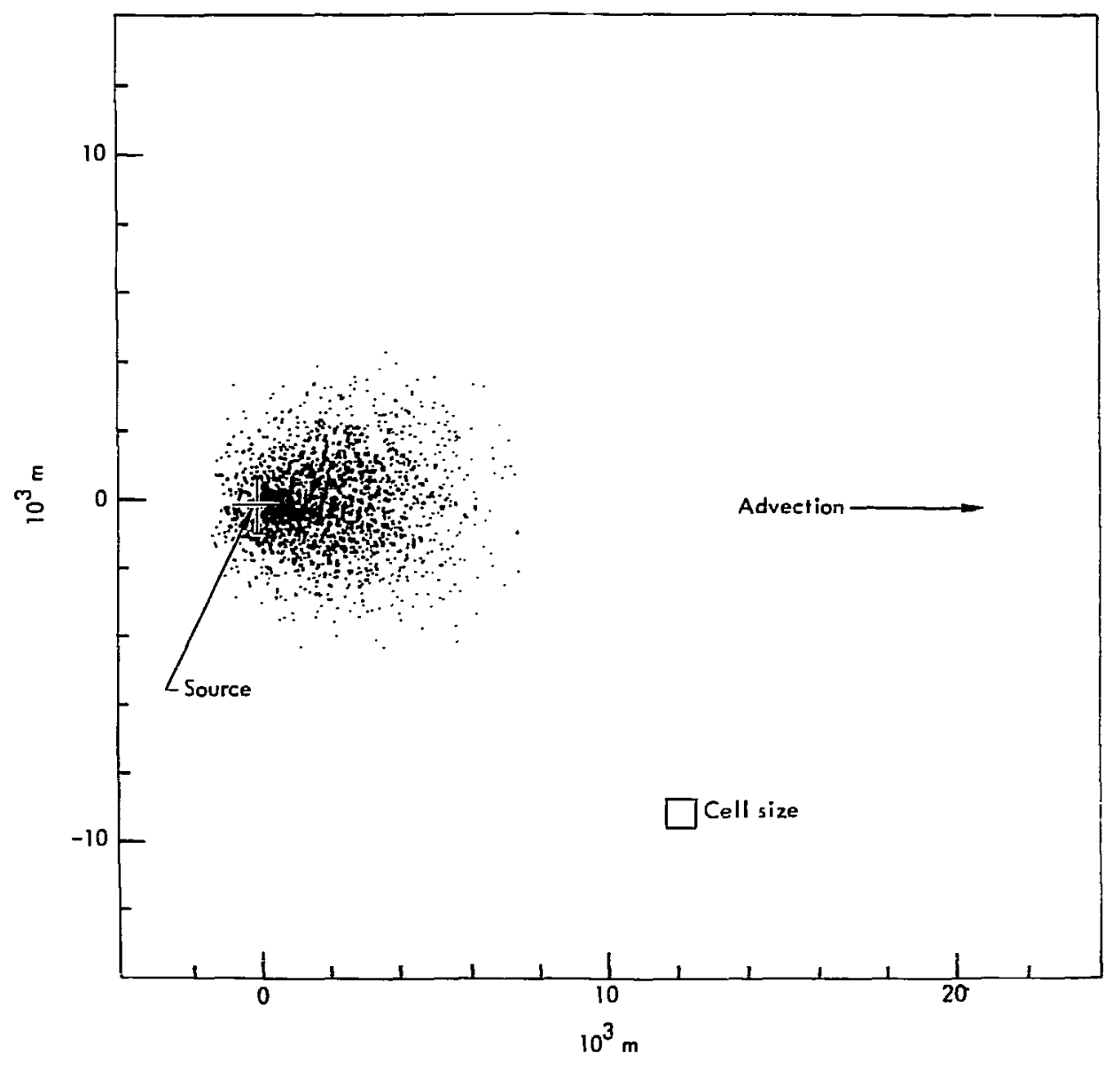

Fig. 30. Particle distribution at cycle 17, $T=1852 \mathrm{~s}, X-Y$ plane, problem 2-3-29G. 


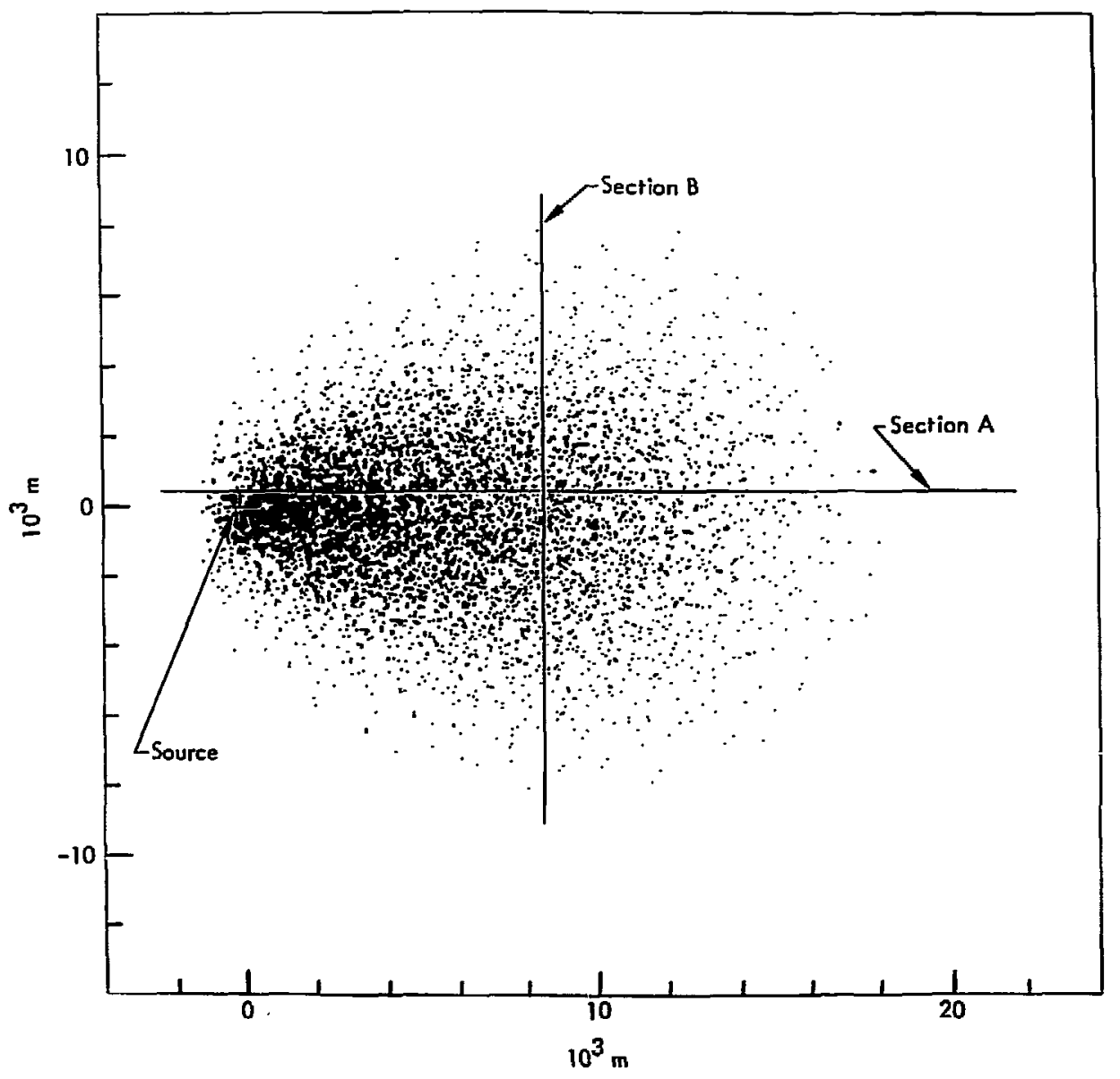

Fig. 31. Particle distribution at cycle $46, T=5526 \mathrm{~s}, \mathrm{X}-\mathrm{Y}$ plane, problem 2-3-29G. Sections refer to planes along which cell center concentrations are sampled for comparison with analytic sclution. 


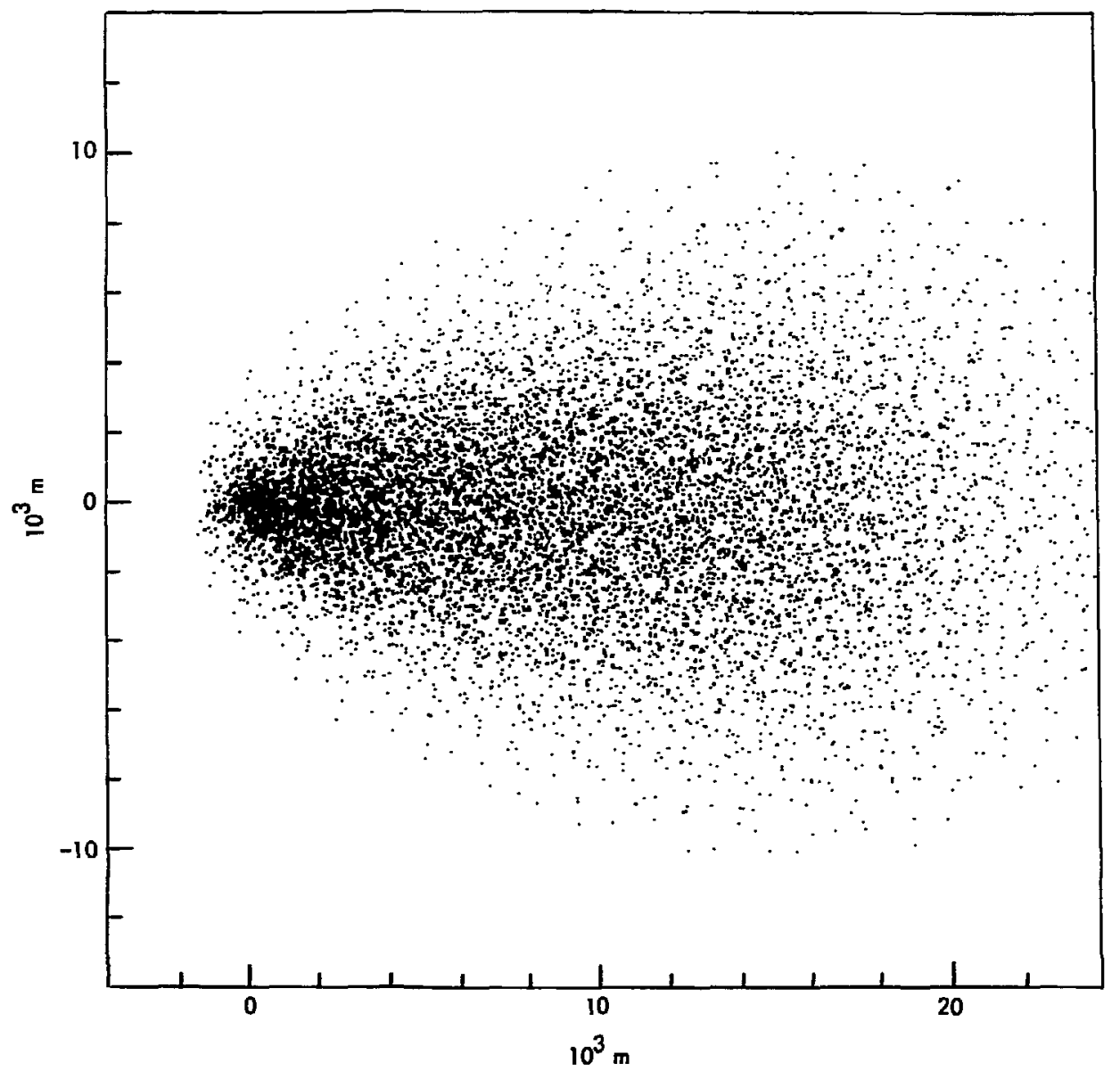

Fig. 32. Particle distribution at cycle 72, $T=9073 \mathrm{~S}, \mathrm{X}-\mathrm{Y}$ plane, problem 2-3-29G. 


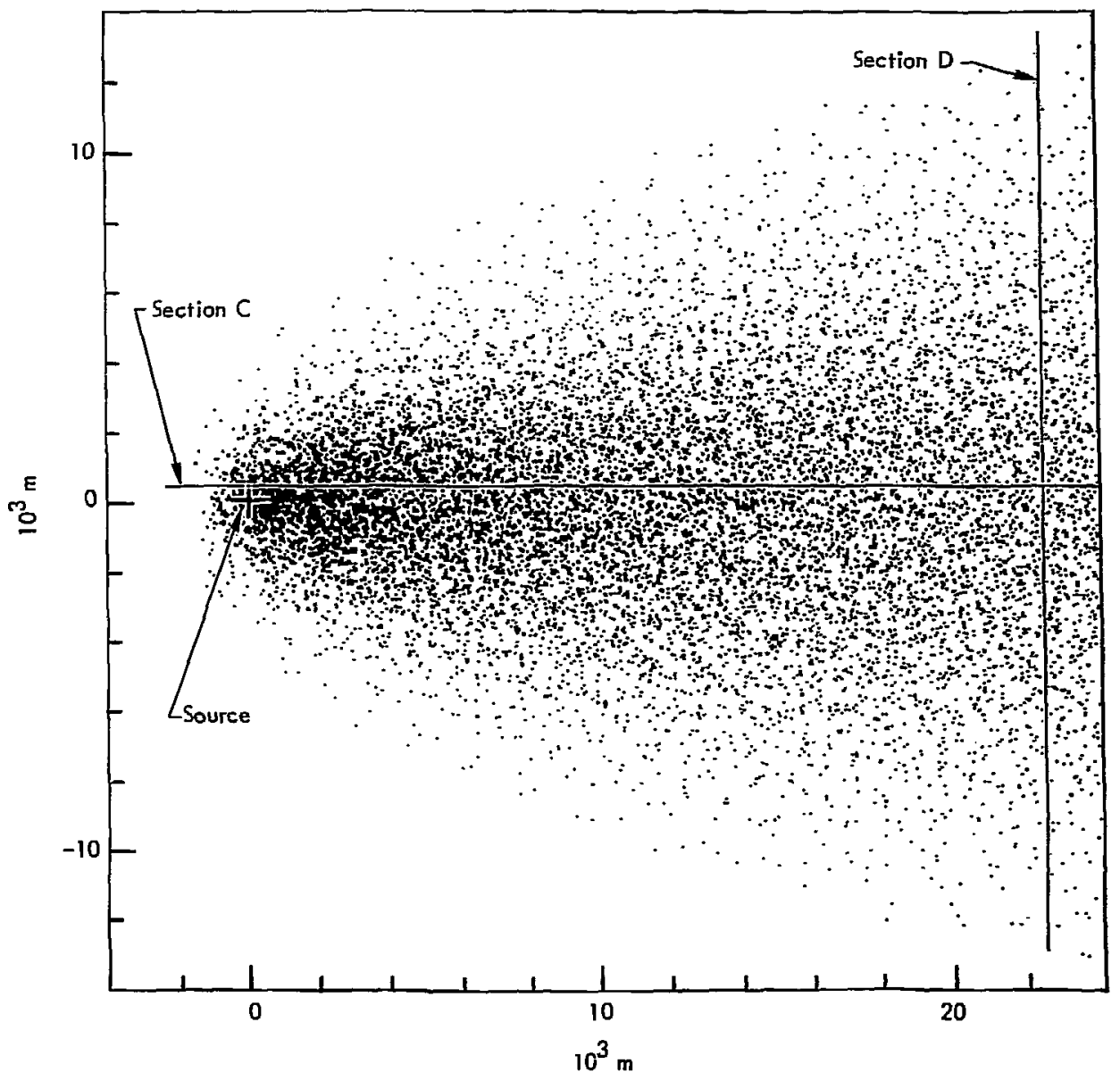

Fig. 33. Particle distribution at cycle 167, $T=9073 \mathrm{~s}, \mathrm{X}-\mathrm{Y}$ plane, problem 2-3-29G. Sections refer to planes at which all center concentrations are sampled for comparison with analytic solution. 


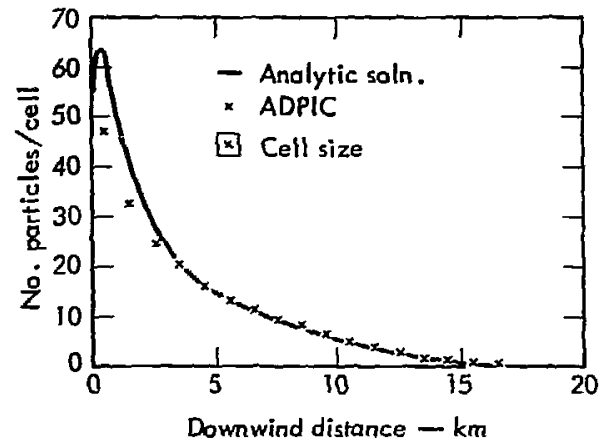

Fig. 34. Plot of cell center concentrations along section $A$, Fig. 31. Continuous source: Diffusion and advection, $\mathrm{U}=2 \mathrm{~m} / \mathrm{s}, \mathrm{K}=1.0$ $\times 10^{7} \mathrm{~cm}^{2} / \mathrm{s}$. Source size:

STD $\sigma 0=20 \mathrm{~m}$, problem 2-3-29G.

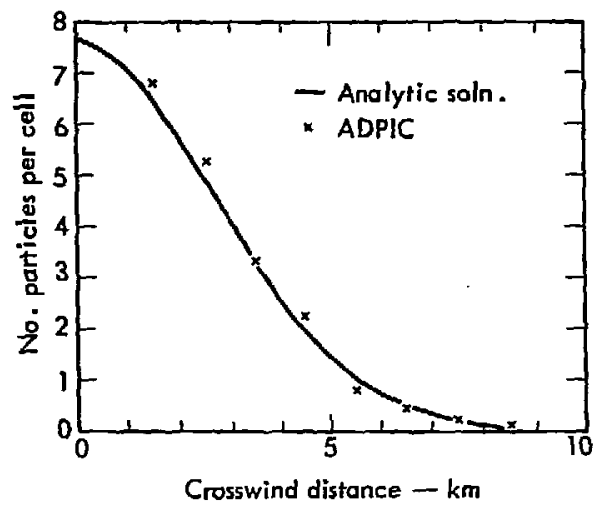

Fig. 35. Plat of cell center concentrations along section B, Fig. 31. Continuous source: Diffusion and advection, $U=2 \mathrm{~m} / \mathrm{s}$. $K=1.0$ $\times 10^{7} \mathrm{~cm}^{2} / \mathrm{s}$, problem 2-3-29G.

The poor agreement on Figs, 34 and 36 near the source point between ADPIC and analytic cell concentrations is due to the fact that the source is not well resolved. However, it is important to keep in mind that while the cell concentration averages of ADPIC in this region are not repre-

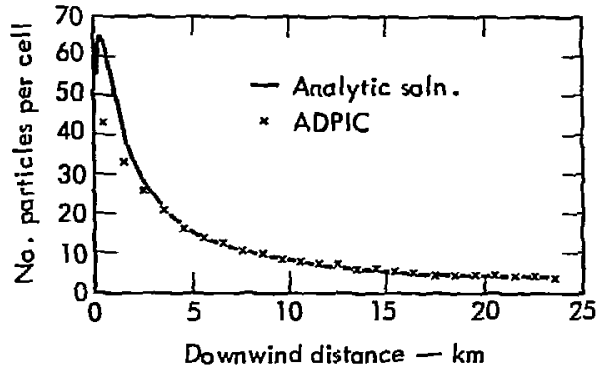

Fig. 36. Plot of cell center concentrations along section C, Fig. 33. Continuous source: Diffusion and advection. $\mathrm{U}=2 \mathrm{~m} / \mathrm{s} . \mathrm{K}=1.0$ $\times 10^{7} \mathrm{~cm}^{2} / \mathrm{s}$, problem 2-3-29G.

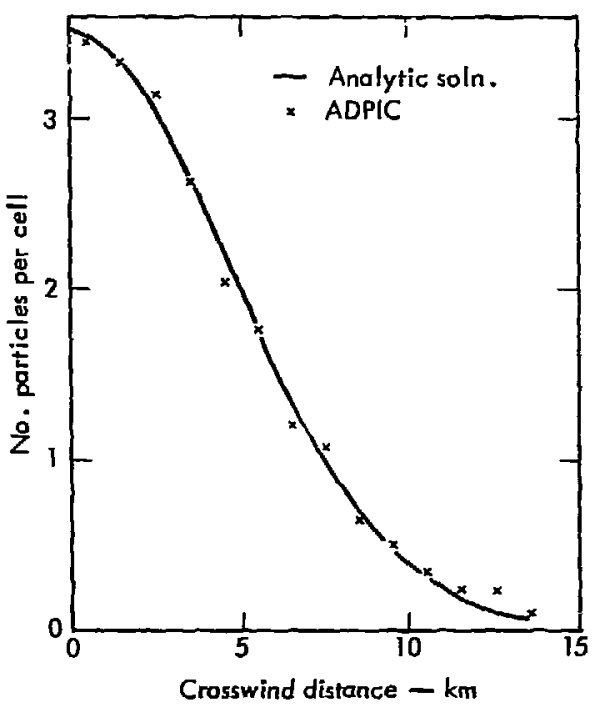

Fig. 37. Plot of cell center concentrations along section $D$, Fig. 33. Continuaus source: Diffusion and advection. $\mathrm{U}=2 \mathrm{~m} / \mathrm{s} . \mathrm{K}=1,0$, problem 2-3-29G.

sentative because of the grid coarseness, they are not used to compute the diffusion of the source particles; rather, the special sub-grid scale source particle diffusion scheme is employed and the actual source particle coordinates as depicted 
in the CRT Figs. $30,31,32,33$ are correct. Thus a proper extended source distribution is eventually provided and the false close-in cell concentrations do not introduce errors into the rest of the grid, as can be seen by the good agreement between ADPIC and the analytic solution at larger distances away from the source.

Problem 2-3-29I is the same problem as 2-3-29G initially. It is run, however, with a larger advection velocity $U_{A}$ $=10 \mathrm{~m} / \mathrm{s}$ in the positive $\mathrm{x}$-direction, resulting in a narrower plume and somewhat different particic budget and total running time. The problem ran 101 cycles and $T=? 325$. There was no need to run it any longer since after about 77 cycles $T=2712 \mathrm{~s}$, the plume reached a steady state with a constant number of particles of about 7900. The total number of particles generated was 12092 at an average generation rate of 119.7 particles/ cycle. A total of 4185 particles left the grid at the end of the problem, leaving 7909 particles in the problem.

Figures 38, 39, 40, 41 and 42 show the particle positions at various times. Figures 43 and 44 compare ADPIC with the analytic solution along sections $A$ and $B$ as located in Fig. 40 at an earlier time when the plume has not yet reached a steady state. Figures 45 and 46 compare ADPIC with the analytic solution along sections $C$ and $D$ as located on Fig. 42 at a time when the plume has reached the steady state. 


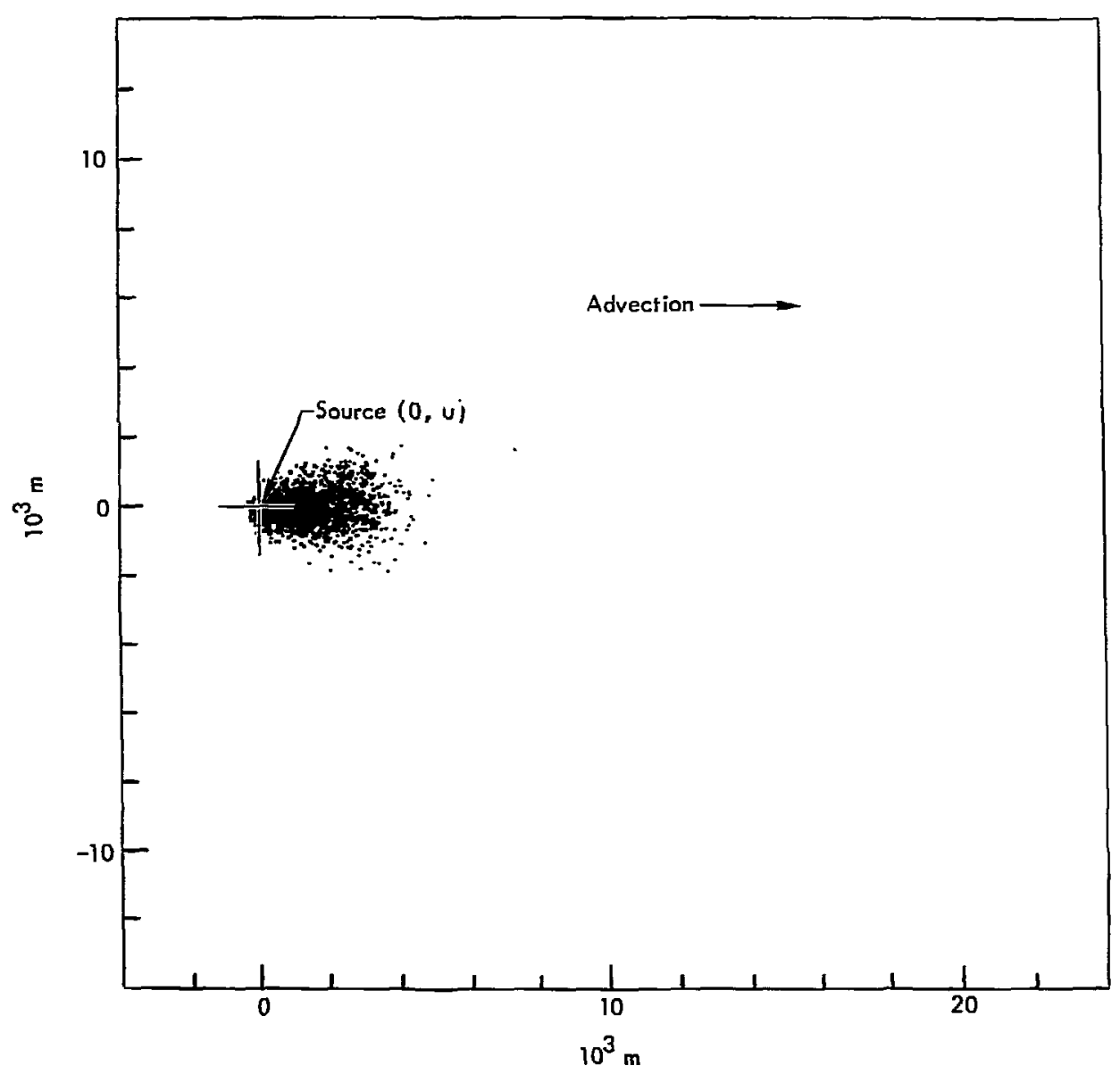

Fig. 38. Particle distribution at cycle 9, $T=306 \mathrm{~s}, \mathrm{X}-\mathrm{Y}$ plane, problem 2-3-29I.

$-46-$ 


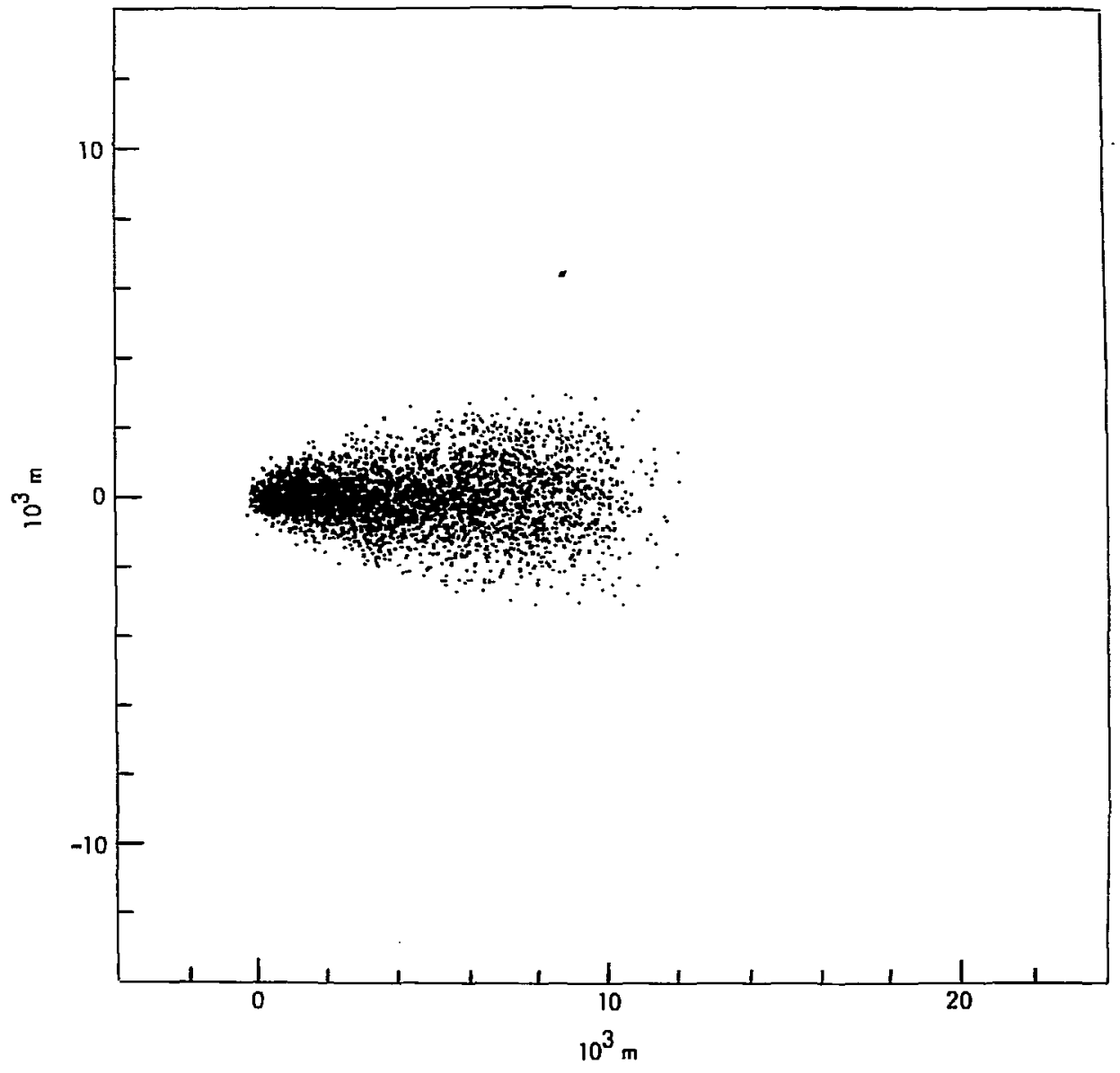

Fig. 39. Particle distribution at cycle 27, $T=924.5$ s, X-Y plane, problem 2-3-29I. 


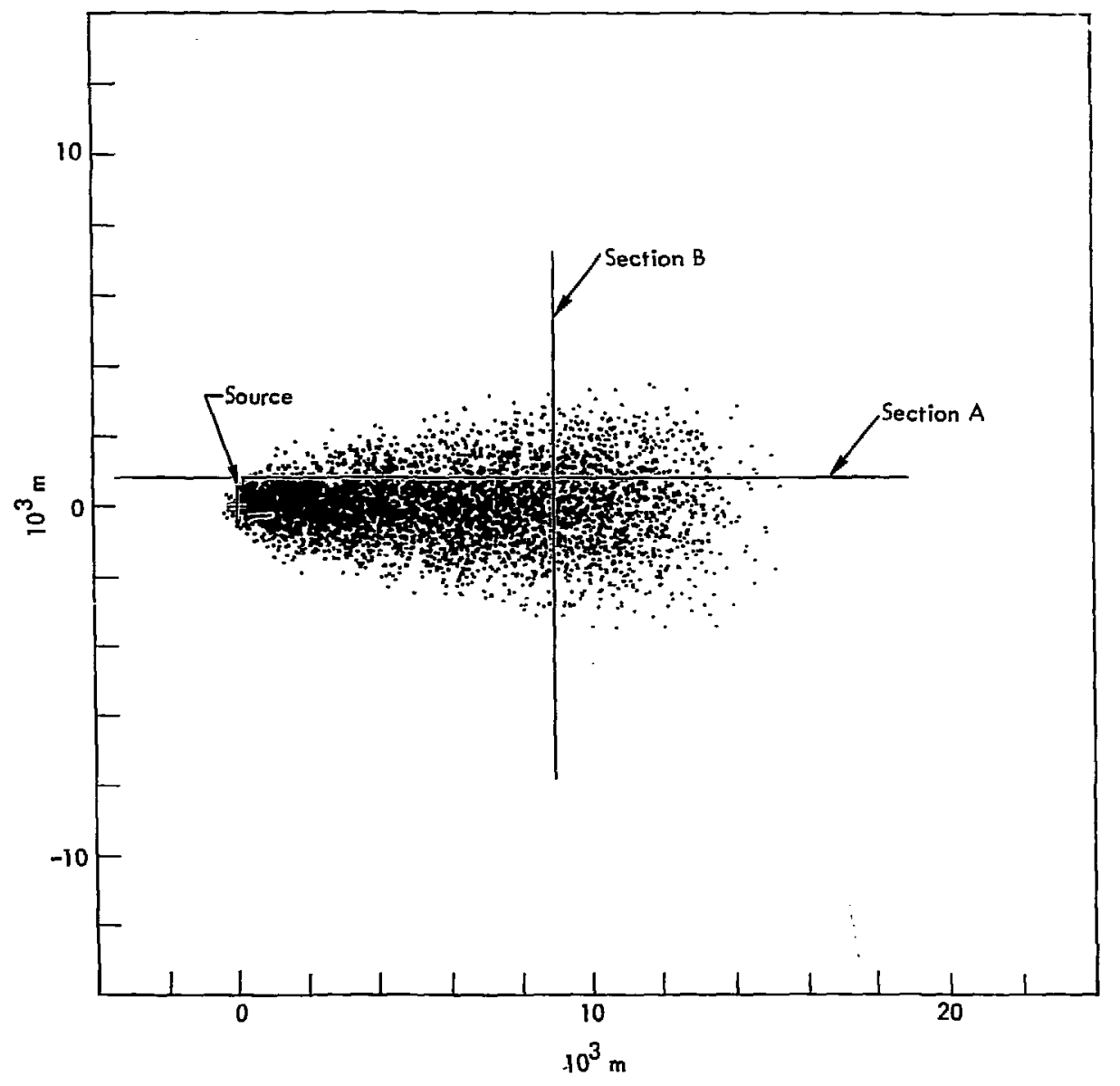

Fig. 40. Particle distribution at cycle 35, $\mathrm{T}=1203 \mathrm{~s}, \mathrm{X}-\mathrm{Y}$ plane, problem 2-3-29I. Sections refer to cross-sectional planes at which cell concentrations are compared to analytic solution. 


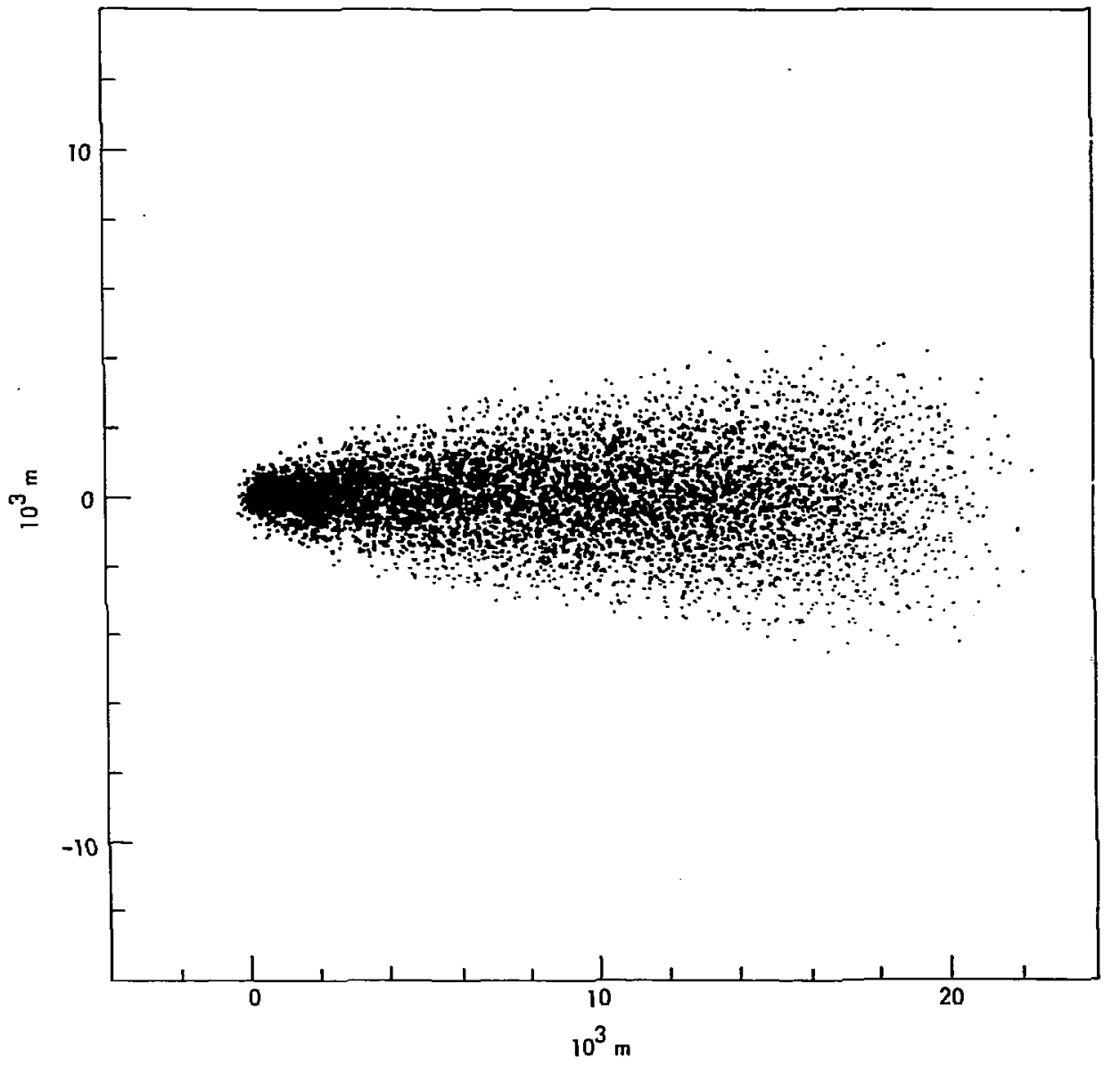

Fig. 41. Particle distribution at cycle 53, $T=1832 \mathrm{~s}, \mathrm{X}-\mathrm{Y}$ plane, problem 2-3-39I. 


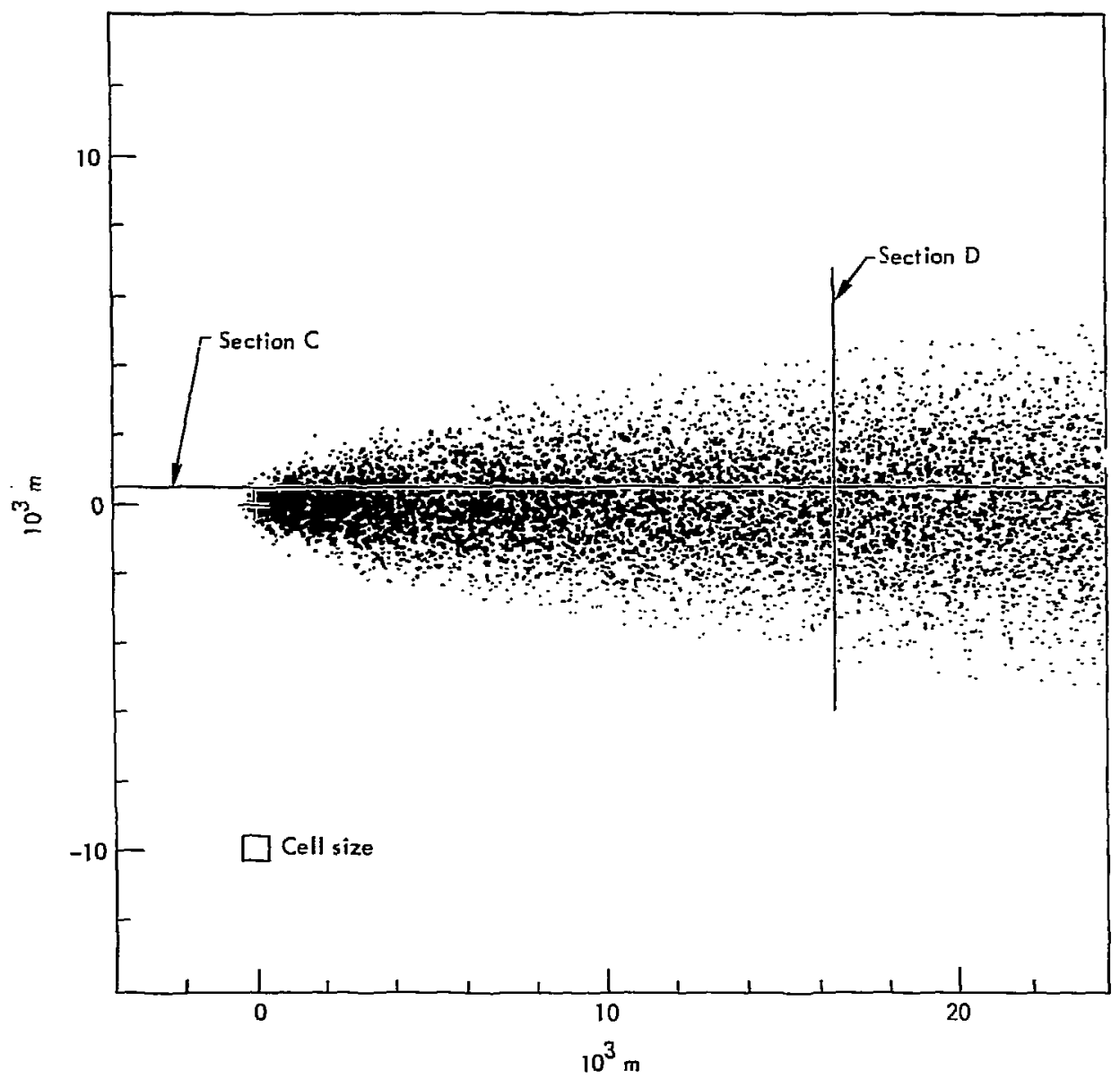

Fig. 42. Particle distribution at cycle $101, \mathrm{~T}=3632 \mathrm{~s}, \mathrm{X}-\mathrm{Y}$ plane, problem 2-3-391. Sections refer to cross-sectional planes at which all concentrations are compared to analytical solution. 


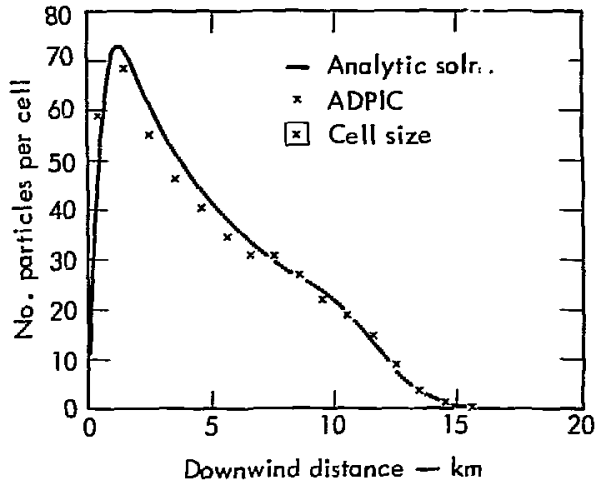

Fig. 43. Plot of cell center concentrations along section A, Fig. 40. Continuous source: Diffusion and advection. $U=10 \mathrm{~m} / \mathrm{s}$, $\mathrm{K}=1.0 \times 107 \mathrm{~cm}^{2} / \mathrm{s}$. Source size: STD $\sigma_{0}=20 \mathrm{~m}$, problem 2-3-29I.

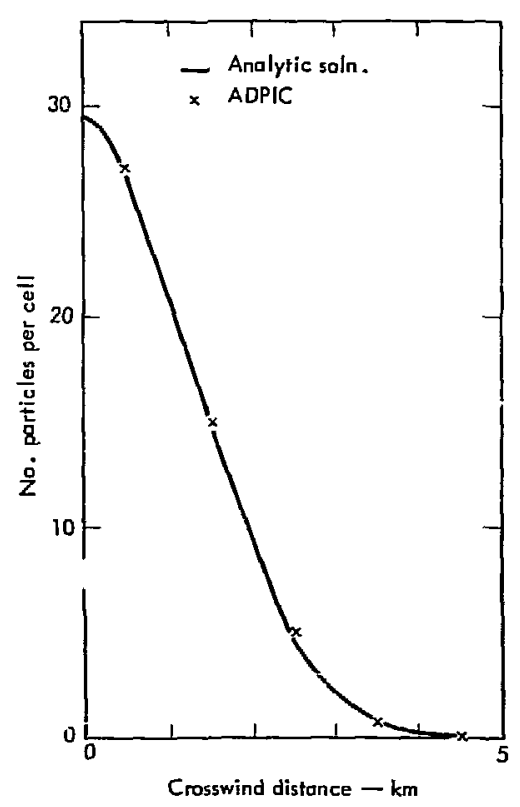

Fig. 44. Plot of cell center concentrations along section $B$, Fig. 40 . Continuous source: Diffusion and advection. $U=10 \mathrm{~m} / \mathrm{s}$, $\mathrm{K}=1.0 \times 10^{7} \mathrm{~cm}^{2} / \mathrm{s}$, problem 2-3-291.

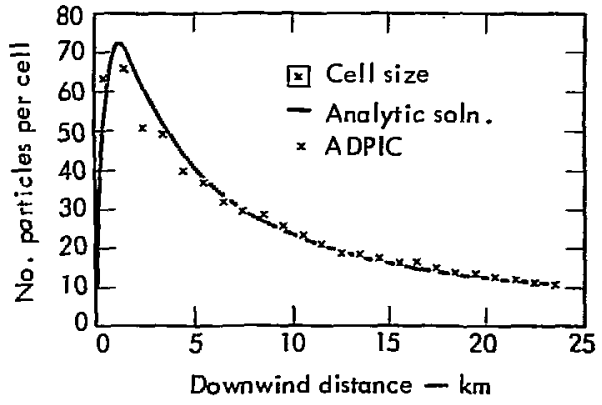

Fig. 45. Plot of cell center concentrations along section C, Fig. 42. Continuous source: Diffusion and advection. $U=10 \mathrm{~m} / \mathrm{s}$, $\mathrm{K}=1.0 \times 10^{7} \mathrm{~cm}^{2} / \mathrm{s}$. Source size: $S T D \sigma_{0}=20 \mathrm{~m}$. Problem 2-3-29I.

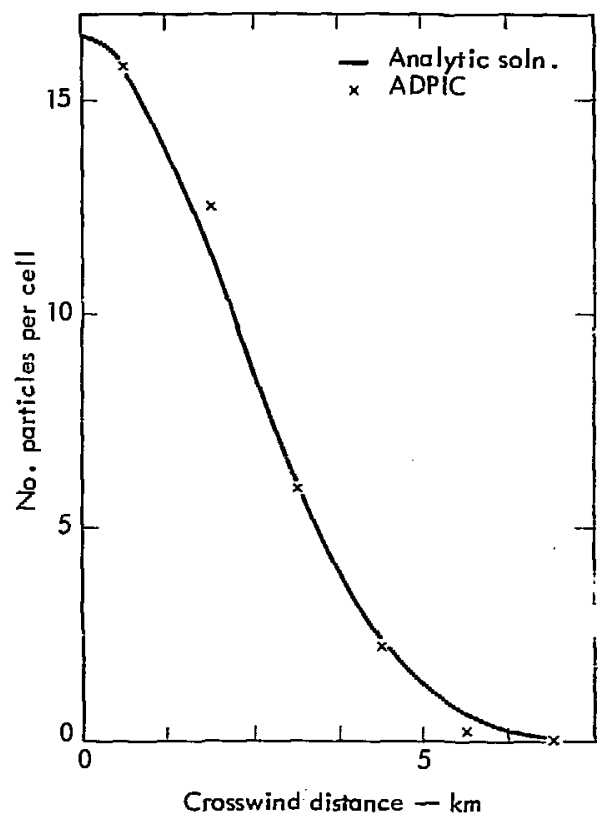

Fig. 46. Plot of cell center concentrations along section D, Fig. 42. Continuous source: Diffusion and advection. $U=10 \mathrm{~m} / \mathrm{s}$, $\mathrm{K}=1.0 \times 10^{7} \mathrm{~cm}^{2} / \mathrm{s}$, problem 2-3-29I. 


\section{VERIFICATION! SUMMARY}

Table 1 summarizes the ADPIC validation problems for a comparison of their agreement with the analytic solutions. The percentage errors listed refer to the deviation of ADPIC from the analytic solutions in terms of standard deviations $\sigma$ of the various concentration distribution cross sections shown in the indicated figures.

Even though the number of cells and particles in the verification problems was moderate, the results indicate that ADPIC diffuses and advects particle distributions over long periods of time, over many orders of $m$ agnitude in size, and for varied specifications of advection and diffusion parameters in thrce dimensions, to withir. a $\pm 5 \%$ error of the analytically caiculated standard deviation for such distributions. If more $\mathrm{c}^{-}$Is and more particles are used, correspondingly smaller errors can be expected.

Two points should be raised. First, the erroi's intıoduced by the lumpiness in the random number generator discussed in the section on Particle Generation under Accuracy of ADPIC adversely affect the accuracy of ADPIC. No detailed

Table 1. Comparison of ADPIC verification problems with the analytic solutions.

\begin{tabular}{|c|c|c|c|c|c|c|}
\hline $\begin{array}{c}\text { (1) } \\
\text { Problem } \\
\text { No. } \\
\end{array}$ & $\begin{array}{c}(2) \\
\begin{array}{c}\text { Coordinated } \\
\text { direction }\end{array} \\
\end{array}$ & $\begin{array}{c}(3) \\
\text { Time } \\
(s)\end{array}$ & $\begin{array}{c}(4) \\
\sigma \underset{n a l y t i c}{(m)} \\
0\end{array}$ & $\begin{array}{c}(5) \\
\sigma \quad \mathrm{ADPIC} \\
\text { (m) }\end{array}$ & $\begin{array}{c}(6) \\
\text { ADPIC errors } \\
(\%)\end{array}$ & $\begin{array}{c}(7) \\
\text { Figure } \\
\text { No. }\end{array}$ \\
\hline \multirow[t]{2}{*}{$3-2-15$} & $\mathrm{x}$ & 286300 & 757 & 770 & +2 & 6 \\
\hline & z & 286300 & 31.2 & 32.0 & +3 & 7 \\
\hline \multirow[t]{4}{*}{$3-3-24 B$} & y & 0 & 204 & 200 & -2 & 9 \\
\hline & $z$ & 0 & 33.4 & 34.5 & +3 & 9 \\
\hline & $y$ & 87720 & $1.37 \times 10^{5}$ & $1.40 \times 10^{5}$ & +2 & 11 \\
\hline & $z$ & 87720 & 4100 & 4200 & +2 & 11 \\
\hline \multirow[t]{4}{*}{$3-3-26$} & $\mathrm{x}$ & 62.54 & 282 & 280 & -1 & 18 \\
\hline & $\mathrm{z}$ & 62.54 & 58.5 & 58.0 & -1 & 19 \\
\hline & $x$ & 6328 & $2.58 \times 10^{5}$ & $2.65 \times 10^{5}$ & +3 & 20 \\
\hline & $z$ & 6328 & 560 & 580 & +4 & 21 \\
\hline \multirow[t]{2}{*}{$2-3-27$} & $\mathbf{x}$ & 24830 & 3150 & 3300 & +5 & 28 \\
\hline & $\mathbf{x}$ & 42450 & 3300 & 3400 & +3 & 29 \\
\hline \multirow[t]{2}{*}{$2-3-29 G$} & y & 5526 & 2620 & 2750 & +5 & 35 \\
\hline & $y$ & 23470 & 4700 & 4550 & -3 & 37 \\
\hline \multirow[t]{2}{*}{$2-3-29 I$} & $y$ & 1203 & 1200 & 1250 & +4 & 44 \\
\hline & $\mathrm{y}$ & 3288 & 1750 & 1800 & +3 & 46 \\
\hline
\end{tabular}

Column (1) contains the problem number. Column (2) lists the direction of sanpling as indicated on the corresponding figure. Column (3) is ADPlC problem time.

Columns (4) and (5) are the standard deviations of the particle concentration distributions for the analytic solutions and the corresponding ADPIC results respectively. Column (6) shows the percentage error of ADPIC, Column (5), with respects to the analytic solution, Column (4). Column (7) refers to the figure in the report which shows the concentration distribution cross sections to which the standard deviations, Columns (4) and (5), pertain. 
study has yet been made of the extent of this effect but as an example, the standard deviation of a puff of particles right after they were generated in ADPIC at $\mathrm{T}=0$ was computed and is shown in Table 1 , problem 3-3-24B. Despite the fact that the random number generator was "instructed" to generate a particle distribution with a standard deviation of 204 and 33.4 respectively, the actually obtained particle placement cor responded to a standard deviation of 200 and 34.5 , producing $2 n$ initial error of $-2 \%$ and $+3 \%$ respectively. Second, the dimensions and diffusion parameters for the various problems are chosen for verification purposes against closed analytic solutions and in some cases do not represent physically meaningful scenarios.

\section{Conclusions}

ADPIC was created with the realization that the study and prediction of the transport, diffusion and deposition of atmospheric pollutants from various sources from local to extended regional scales requires a three-dimensional approach to computer modeling. Most air pollution scenarios involve timeand space-varying advection fields (shear) and diffusion parameters, topography, precipitation and gravitational effects for a variety of active or inert sources and are inherently three-dimensional in nature.

ADPIC was developed with capabilities to treat all these aspects of pollutant dispersal over short or long times with good accuracy for any specified source term, with the exception, for the present, of photochemistry. The pseudo-velocity and particle-in-cell method was chosen for ADPIC chiefly because of its advantage of eliminating the fictitious diffusion inherent in purely Eulerian codes. The other big advantage of this method is, that with the coordinates, mass, activity and "age" of each particle bnown at all times, the treatment of dry deposition, washout from rain, radioactive decay, radioactive cloud-dose calculations and multiple instantaneous or continuous sources of various sizes and duration, becomes very convenient.

With the development of the threedimensional, mass-consistent wind-field model MACAW, ${ }^{26}$ which is used to provide the full three-dimensional space and timevarying advection field to ADPIC, pollutant dispersion studies of any desired complexity including stratified shear flow and calm conditions can be undertaken. By the same token, ADPIC can accommodate the full time- and space-varying diffusivity tensor $K_{i j}$, but currently only the usual three diagonal terms are used to describe scale-dependent atmospheric diffusion.

ADPIC has undergone an extensive verification effort, the most important cases of which are describud in this report, and it has been shown to compare with the corresponding analytic solutions to within a few percent. Since meteorological and pollution data frequently considerably exceed a few percent error, ADPIC can be considered a sensitive 
tool for the full-scale numerical study of pollutant dispersal in the atmosphere."

Since the writing of this report ADPIC has been applied extensively on the regional scale in the USAEC Reactor Safety Study (Prof. Rassmussen Panel) and it will be furthe- verified against reFional tracer release experiments during the coming fiscal year.
Although ADPIC has so far not been applied to water pollution problems, there is no reason why it could not be used. together with the appropriate advection how field and diffusion parameters, to studj the dispersion parameters, to study the disperson of pollutants in water.

\section{Acknowledgments}

I would like to thank all those members of $\mathrm{G}$-group who have contributed their advice and critirism. My special thanks go to l.conard L.awson who programmed the code with skill and the flexibility so important turing the cevelopment prase of a large research cude. 


\section{References}

1. J. E. Weleh, F. H. Harlow, J. P. Shannon, and B. J. Daly, The MAC Method, Los Alamos Scientific Laboratory Rept. LA-3425 (1965).

2. A. A. Amsden, The Particle-in-Cell Method Sor the Calculation of the Dynamics of Compressible Fluids, Los Alamos Scientific Laboratory, Rept. LA-3466 (1966).

3. R. C. Sklarew, A. J. Fabrik, and J. E. Prager, A Particle-in-Cell Method for Numerical Solution of the Aimospheric Diffusion Equation, and Application to Air Pollution Problems, Systems, Science and Software, La Jolla, Californis, Rept. 3SR-044 (1971).

4. W. K. Crandall, C. R. Molenkamp, A. L. Williams, M. M. Fulk, R. Lange, and J. B. Knox, An Investigation of Scavenging of thadioactivity from Nuclear Debris Clouds : Research in Progress, Lawrence Livermore Laboratory, Rept. UCRI--51328 (1073).

5. T. v. Crawiord, A Computer Program for Calculating the Atmospheric Dispersion of Large Clouds, Lawrence Radiation Laboratory, Rept. UCRL-5017g (I9G6).

6. G. K. Batchelor, "Kolmogororr's Theory of Locally Isotrapic Turbulence," Proc. Cambridge Phil. Soc. . 43, 533 (1947).

i. G. K. Batchelor, "The Application of the Similarity Theory of Turbulence to Atmospheric IJifrusion," Quart. J. Roy. Metcorol. Soc., 7G. 133 (1950).

3. G. K. Batchelor, The Theory of Ilompgereous Turbulence, (Cambridge University I'ress, New Jork, 1053).

9. A. M. Oubkhov, 19+1, "Energy Distribution in the Spectrum of lurbulent Flaw," lav. Akild. Nauk, Geogr. i Civoliz.. 5, $\$ 53(19+1)$.

10. A. S. Munin, and A. A1. Obukhox, I95t, "Basic Laws of Turbulent Mlixing in the Ciround L.ayer of the Mlmosphere," akad. Nauk. Lish Goorlz. Inst. Ir., 151. $163(195+)$.

II. II. A. lanursky, "Iketermination of siress from Wind and Temperature Measurements," Quart. J. Hov. Molcurol. Sac., th9. Bs (1963).

12. J. I.. 1.umley, and II. A. Panorsky, the Struclure of Amospherie Turbulenee, fultersicience, New lurk, (gGt).

13. W. P. Btliott, "laytime Temperatura Profles," J. Almos. Sct., 23, Gin (1968).

14. H. Charnoek, "l-lux Gradfent Relations Near the Giround in Lnstable Colditions," Quarl. J. liay. Mlutuorul. Soc. 93, g7 (1967).

15. A. J. Iyer, 1065, "The filux Ciradient Relation for Turbulent lleat Transfor in the l.uter Atmosphere," Quart. J. Iloy. Mleteorol. Soc., 91, 151 (190̈5).

16. A. J. 1ser, "ghe furbutent Transport of fleat and Viater vapour in an Linstable

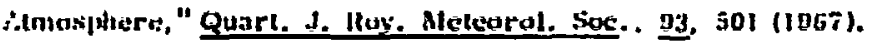

17. A. 1. Nyer, "An Bvaluation or bitly Flux Variation fu the Mtmospherte bountary

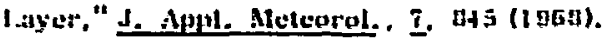


18. W. C. Swinbank, "A Comparison Between Predictions of Dimensional Analysis for the Constant-Flux Layer and Observations in Unstable Conditions," Quart. J. Roy. Meteorol. Soc., 94, 460 (1968).

19. J. A. Businger, J. C. Wingaard, Y. Izumi and E. F. Bradley, "Flux Profile Relationships in the Atmospheric Surface Layer," J.Atmos. Sc:., 28, i81 (1971).

20. G. C. Holzworth, "Estimates of Mean Maximum Mixing Depth in the Contiguous United States," Monthly Weather Rev. . 92, 5, 235 (1964).

21. D. H. Slade, Meteorolugy and Atomic Energy (U.S. Atomic Energy Commission, Technical Information Division, Oak Ridge, Tenn., 1968).

22. R. Reiter and R. Sladkovic, "Control of Vertical Transport of Aerosols Between 700 and 3000 Meters by Lapse Rate and Fine Structure of Teraperature," J.

Geophys. Res. 75, 3065 (1970).

23. F. Pasquill, Atmospheric Difrusion, (D. Van Nostrand, London, I562).

24. F. Pasquill, "Atmospheric Dispersion of Pollution," Quart. J. Roy. Meteorol. Soc. . 97, 369 (1971).

25. F. A. Gifrord, Private communication of lecture notes, 1973.

26. M. II. Dickerson. A Mass-Consistent Wind Field Model for the San Francisco Bay Area, Lawrence Livermore Laboratory, Rept. UCRL_-74265 (1973).

27. J. J. Walton, 1973, "Scale-Dependent Dirrusion," 3. Appt. Metcorol. 12. 547 (1973).

2B. A. F. Qunsada and M. A. Macheod, "The Metermination of Jirfusion Coefficients in a Shearing Flow by Chemlal Tracer Techniques," Proc. Symp. Air Polluzion, Turbulence and Dirrusion, Dec, $i-10$, 1971 , New Mexicu, pp 38t-39l.

20. G. J. Haltiner and 1\%. K. Martin, Dynamical and Physical Meteorology, (MeGrawllill, New York, I95i). 